\title{
Experimental Investigation of Reciprocally Supported Element (RSE) Lattice Honeycomb domes Structural Behaviour.
}

\author{
J. P. Rizzuto*
}

School of Computing and Engineering, University of West London, United Kingdom.

(Tel: 0208231 2638, email: joe.rizzuto@uwl.ac.uk)

\begin{abstract}
The honeycomb configuration of the many Diamatic dome patterns available is particularly convenient for reciprocally supported element (RSE) transformation. This is due to there being only three lattice bar elements intersecting at any apex, irrespective of the number of the bar elements used to form the crown polygon. RSE transformation effort therefore is both reduced and simplified compared to some RSE forms. To inform the understanding of the structural behaviour of honeycomb RSE lattice domes, a study comparing structural modelling predicted behaviour with monitored behaviour in the laboratory was carried out. This investigation focused on the structural behaviour of a RSE lattice honeycomb dome structure under applied static loading. The first part of the study included configuration processing, structural modelling and analysis. The second part involved manufacture, construction and monitored behaviour of the dome in the laboratory. The creation of the selected RSE honeycomb lattice structure together with the structural modelling and experimental outputs are presented and discussed. Predicted displacements and stresses are compared under varying applied loading, boundary support conditions and connection stiffnesses. The locations of the onset of local yielding is considered and discussed. The applied loading did not exceed the tube yield stress according to the von Mises ductile material failure criterion indicating that the dome behaviour observed was elastic.
\end{abstract}

Keywords: reciprocally supported elements, reciprocal structures, honeycomb domes, space structures, structural behaviour.

*Corresponding Author, email: joe.rizzuto@uwl.ac.uk

\subsection{Introduction}

Element cluttering typically evident in the crowns of the Ribbed, Schwedler and the Lamella family of lattice domes, as shown in Figure 1 (a) to (c), may render their reciprocally supported element (RSE) transformation challenging. The honeycomb configuration of the many Diamatic dome patterns available [1] is particularly convenient for RSE transformation. This is due to there being only three lattice elements intersecting at any apex irrespective of the number of elements used to form the crown polygon. See Figure 1 (d) to (e). RSE transformation effort is both reduced and simplified compared to some other RSE forms [2 - 16]. Honeycomb configurations can be similar in appearance to geodesic domes when five lattice elements are used to form the crown polygon. See Figure 1 (d).

To augment the understanding of the structural behaviour of RSE honeycomb lattice domes, a study comparing structural modelling predicted behaviour with monitored behaviour in the laboratory was carried out. This investigation focused on the structural behaviour of a RSE lattice honeycomb dome structure under applied static loading. The first part of the study included the configuration processing, structural modelling and analysis. The second part involved manufacture, construction and monitored behaviour in the laboratory. 


\subsection{Diamatic Honeycomb Domes RSE Transformation}

The basic elemental lattice honeycomb domes considered for transformation into equivalent RSE domes were created using Formian [1, 17]. In Formian, the parameters controlling the span and rise at the dome crown is the sweep angle that is defined as half the central angle at the origin of the elemental dome sphere. In the initial studies, a sweep angle range of $30^{\circ}$ to $70^{\circ}$ was considered.

The constraints of the test rig in the Engineering laboratories at the University of Greenwich, Chatham, (UOG) dictated the size of the dome that could be considered. A dome diameter of the order of $3.2 \mathrm{~m}$ with a rise to the crown of approximately $1.0 \mathrm{~m}$ could be accommodated. A sweep angle of 60 degrees was found to provide the desired initial dome diameter and rise.

Dome construction was informed by previously acquired experience $[18,19,20]$. It was anticipated that circular hollow section (CHS) tubes of $48.3 \mathrm{~mm}$ diameter would be used and these would be bolted together with $12 \mathrm{~mm}$ diameter bolts. The bolts would pass through $13.0 \mathrm{~mm}$ diameter clearance (oversized) holes drilled through the CHS tubes. Saddleback washers with a minimum thickness of $0.85 \mathrm{~mm}$ would be utilised to enable accurate seating and location of the bolts and RSEs.

The rotation method was used for the RSE transformation [2, 21, 22]. This required the elementary dome lattices to be rotated about a normal vector, $\mathrm{N}$ passing through the dome origin and lattice elements midpoints. A rotation angle of $15^{\circ}$ was selected as a starting point. The common perpendiculars between each pair of skew lines that were formed about each apex were used to generate the initial eccentricities. Formian [1] and Rhinoceros [23] were used to carry out the RSE transformation. Figure 2 illustrates the transformed honeycomb lattice dome into the equivalent RSE structure.

\subsection{Transformation Optimisation}

A $50 \mathrm{~mm}$ target eccentricity value, between the CHS centroidal axes, was selected for all the dome connection locations. This required the initial $15^{\circ}$ rotation eccentricity values to be modified $[2,21$, 22]. To keep the optimisation time required to achieve this to a minimum, the accuracy of the final eccentricity values obtained was considered sufficient at $50 \mathrm{~mm}$, plus (+) $2.5 \mathrm{~mm}$ or minus (-) $0.5 \mathrm{~mm}$. Small dimensional differences could be made up with shims in the form of parallel faced flat washers $[2,21]$. Following this optimisation process the final RSE dome span and rise was accepted as 3066 $\mathrm{mm}$ and $894 \mathrm{~mm}$ respectively. See Figure 3 for details of the initial and optimised eccentricity values together with the required shim thicknesses and their locations.

\subsection{Structural Modelling}

The dome structure was modelled and analysed using Oasys General Structural Analysis, (GSA) software with 3-dimensional and finite element capabilities [24].

It was anticipated that it may be problematic to model some of the experimental features such as the actual support conditions and the bolted connections. A range of possible scenarios were considered therefore as, for example, welding end plates to the boundary support legs to give fixed or pinned end conditions was in this instance considered uneconomic for a structure of this scale.

The static-linear analysis of the dome under load conditions was carried out in stages. The first stage considered five different analysis models [25]. These five models were refined to eight analysis models in order to ensure that all of the possible variations were captured and these are now considered here. 


\subsection{Boundary support conditions}

The boundary support conditions anticipated assumed that: (i) the support legs may be free to move laterally as none would be mechanically fixed in position, and (ii) minor geometric self-adjustments would take place due to the initial loading and unloading procedure $[2,25]$.

Determination of boundary support stiffnesses was determined in stages. Stage 1 assumed that under an elastic load value all of the boundary support nodes, S1 - S10, shown in Figure 3 were fixed in position and pinned from which the reaction forces, Fx and Fy were obtained. Stage 2 assumed the same load conditions as stage 1 except node S2 that was given a horizontal roller support from which displacements, Ux2 and Uy2 were determined. All of the remaining displacements, Ux and Uy for S3 to $\mathbf{S 1 0}$ were each determined sequentially as outlined in stage 2 . The resulting spring stiffnesses are as shown in Tables 1 and 2.

\subsection{Connections between CHS elements}

Numerical modelling of RSE bolted connections between CHS arrangements is complex and therefore required careful consideration [2, 26 - 28]. The connection depths were based on the optimised 50 $\mathrm{mm}$ eccentricity value. Two GSA connection model types were considered as illustrated in Figure 4.

Connection model type 1 utilised a GSA 'beam' element [24, 25] that was straightforward to apply. In order to avoid analysis instability these were considered as fixed to adjacent pairs of CHS centroidal axes. This however resulted in very high elastic stresses being indicated in the bolts under the proposed loading.

To better represent the behaviour of the joints, an alternative model was adopted whereby connection model type 2 utilised GSA 'spring' elements. Separate translational and rotational spring properties were required to be determined for these. The two directional springs elements were attached between the two single connection nodes on each adjacent pair of CHS centroidal axes forming the RSE module circuits [24, 25].

The translational and rotational spring properties were determined by generating finite element (FE) models of a representative connection between two RSE tubes. Initially generated FE models [25] were investigated and new more refined FE models were developed. Individual FE tube ring models of various width, with and without the clearance holes, were also investigated. The ring width increments ranged from $10 \mathrm{~mm}$ to $120 \mathrm{~mm}$. All FE models used GSA 'Quad4' 2D shell elements. Figure 5 shows the axial displacements and moment $x, y$ and $z$-axis component results under loading for the refined FE connection models. Localised stiffening was used at the applied loading positions for the local y'- and z'-axis moment displacements. Influencing parameters included the positions and orientation of the applied load relative to the CHS axes and the associated support conditions applied.

Twelve RSE bolted connections types [e1 - e12] were present in each of the dome's five zones [Z1 25] as shown in Figure 3. These connections were individual in terms of both their relative orientations and rotations. In order to establish how significant these variations were, the target eccentricity and a single orientation angle, initally investigated at 45 degrees, was modified to an averaged 60 degrees, were used. This orientation was adopted to represent the twelve connections between the upper and lower tubes.

The connection rotational and the translational stiffness properties were determined using $k_{R}$ from the slope of the $M / \theta$ curve, and $k_{T}$ from the slope of the $F / \delta$ curve, respectively. Where, $M$ and $\theta$, are 
the applied moment $(\mathrm{kNm})$ and associated rotation angle (radians); $\mathrm{F}$ and $\delta$, are the force $(\mathrm{kN})$ and associated displacement $(\mathrm{m})$. Typical translational and rotational spring values initially used can be found in [25]. For this study, a number of ring 'slices' under the saddleback washers load transfer areas were considered. Rings with and without the clearance bolt holes were investigated. For each individual tube these were assumed to act as springs in parallel to determine their total equivalent spring stiffness.

The upper CHS orientation was taken as being at 60 degrees to the lower CHS. The upper and lower tubes were considered as springs in series and their equivalent total translational spring stiffness was determined. The rotational spring stiffness about the local vertical axis for this study was taken as effectively zero as it was assumed that no frictional resistance between the back-to-back saddleback washers could be developed. The other rotational spring parameters were determined using the FE models shown in Figure 5. RSE connection stiffnesses determination is the subject of further detailed study. See Table 3.

The boundary and connection conditions, refined for the eight analysis models, are shown in Table 4.

\subsection{Loading conditions and selected monitoring locations}

Ten load cases were considered in the analysis for this study for each of the eight analysis models shown in Table 4. The first two load cases, LC1 and LC2, were for the permanent dead loading. LC1 consisted of the self-weight of the dome structure and accounted for the CHS tubes, saddleback washers with nuts and bolts. LC2 consisted of the self-weight of the load transfer beam with accompanying two end bearings support mechanisms. These were attached to the dome structure at the loading locations at the midpoints of two adjacent crown tube elements.

The remaining load cases LC3 - LC10, consisted of the variable imposed applied load. The Load was to be applied on the two selected tubes shown in Figure 6 each with a maximum of $4.0 \mathrm{kN}$ and applied in increments of $0.5 \mathrm{kN}$ up to a maximum total load of $8 \mathrm{kN}$.

\subsection{Analysis Assumptions}

Importing the optimised RSE dome model from Rhinoceros [23] into the GSA environment for global bar-and-node analysis automatically defined the nodes and their numbering. The element types and topology as well as the constraints and support conditions required to be defined by the user [24].

The GSA 'beam' property types used in the GSA analysis defined the $48.3 \mathrm{~mm}$ diameter $4.0 \mathrm{~mm}$ thick CHSs and the 12 and $15 \mathrm{~mm}$ diameter grade M8.8 bolts [29] of solid cross-section used for connecting the CHSs together in closed triangulated circuits. Two property types defined the translational and rotational stiffnesses used.

The applied loading load cases, LC3 - LC10, output was used for monitoring comparisons [25].

\subsection{Experimental Investigation Setup}

The dome structure was positioned within a test frame with the ten inclined RSE boundary support legs reacting on the wide flanges of web-stiffened steel beams located on the floor of the UOG Engineering laboratories. The support legs ends were machined so that they all sat in a horizontal plane. See Figures 7 and $8(a)$. The test dome structure was structurally stable due to the bolted triangulated module circuits and as such no structural bracing in the form of additional elements was required. 
Single bolts were used to connect the RSEs to one another. Clearance holes, through which the bolts passed through, were sized to comply with the Eurocodes [29] and ensured that sufficient tolerance was available for ease of assembly. Saddleback washers were used to ensure that the applied loading was efficiently transferred between the CHS elements. Grade S275 steel was specified for the test structure tubes [30].

Strains were monitored using Micro-Measurements electrical resistance (ERS) three-element rectangular stacked construction rosettes [31] bonded at the locations shown in Figure 6 . The matrix size of the rosettes was $13.0 \mathrm{~mm}$ long by $15.2 \mathrm{~mm}$ wide with the gauges arranged in a $45^{\circ}$ pattern.

The rosettes were located on the upper surfaces of the tubes of the module circuits shown in Figure 6 in order to determine the state of stress at those points under the applied loading conditions. The location of the rosettes was selected as the mid-length along the central tube axis between the leading and trailing bolted connections. This was in order to avoid areas of potential stress concentrations. See Figures 8 (b) and 9.

Demec mechanical strain gauges [32] were bonded $50 \mathrm{~mm}$ either side of the centre of strain gauge $C$ shown in Figure 9 along the tube centre line to simultaneously check on the Adams data logger [33] output as the load testing was being carried out at location vM3.

To ensure elastic behaviour, vertical displacements were monitored with Linear Variable Differential Transformers (LVDTs) [34] at intervals of loading and unloading. See Figures 10 and 11. LVDTs were used to monitor the tube centroidal local $x$-axes displacements as shown in Figure 11 (b) in order to ensure that the LVDT monitored vertical displacements along the global z-axis were not compromised under the range of the applied loading.

Several initial loading and unloading tests were carried out in order to verify elastic behaviour. This also allowed any necessary minor bolted connections readjustments to be made. Two full test sets were carried out after this procedure to ensure consistency in the recorded output. All of the test equipment was calibrated to ensure reliability $[2,19]$.

The dome was orientated such that it was centrally located below the load transfer assembly. Loading of the dome was via a manually operated hydraulic pump connected to a hydraulic ram that applied the required loading to a spreader beam supported on ball-joints and specially formed attachments for the CHS. The applied loading was controlled via a load cell incorporated between the hydraulic pump and the ram. See Figure 10.

The load range was applied to the centres of two, arbitrarily selected, of the five CHS elements forming the dome crown. See Figures 6, 10 and 11.

\subsection{Applied Loading}

For the test configuration considered, the applied load that would not initiate localised material yield behaviour was determined as $8 \mathrm{kN}$. This upper limit of applied load would therefore ensure that the developed strains remained within the elastic range of the material.

The total self-weight of the dome assembly was $143 \mathrm{~kg}$ and the self-weight of the load transfer beam assembly was $10 \mathrm{~kg}$. See Figures 10 and 11.

The magnitude of the applied loading was comfortably below the anticipated yield strength of the material used for the construction of the test dome. For the selected grade of steel of S275, the same material property values were used in both the GSA analysis and the calculations emanating from the 
recorded laboratory strain results used to determine the von Mises stresses. Typical values used are given in section 5.2 .

\subsection{Experimental Output}

The initial state of strain due to the dome structure self-weight and the transfer beam assembly was taken as the datum for subsequent readings. The recorded strains were a result of the applied loading only therefore.

\subsection{Global Analysis and Experimental Results}

The displacements and Von Mises stress results obtained from the GSA global analyses were compared for accuracy and reliability with the displacements and strains obtained from the experimental investigation. These are now summarised and considered for the monitoring locations for the vertical displacements, Uz1 to Uz4 and monitored von Mises stress, vM1, vM2 and vM3 shown in Figure 6.

\subsection{Displacement, Uz}

The overall global displacement behaviour of the eight dome structure models considered in the analysis for the applied load $1-8 \mathrm{kN}$ are shown in Figures 12 and 13.

The vertical displacement graph plots shown in Figures 14 and 15 illustrate the predicted and monitored structural responses for the applied load range. These can be seen to be linear elastic. This response was confirmed by observing that the monitored displacements at Uz1 - Uz4 were similar during loading and unloading of the dome.

\subsection{Von Mises Stresses}

From the ductile material failure criterion, [35] a simplified approach is used in GSA [23] to determine the von Mises stresses, $\sigma_{\mathrm{VM}, \mathrm{A}}$ where:

$$
\begin{aligned}
\sigma_{\mathrm{vM}, \mathrm{A}}=\left(\sigma_{\mathrm{xx}}{ }^{2}+3 \tau_{\mathrm{xy}}{ }^{2}+3 \tau_{\mathrm{xz}}{ }^{2}\right)^{0.5} & \leq \text { yield strength of material, } \sigma_{\mathrm{y}}=275 \mathrm{~N} / \mathrm{mm}^{2}
\end{aligned}
$$

Figures 16 and 17 show the global von Mises stresses distribution in the eight analysis models.

The von Mises stresses were determined using the stacked rosette gauges $A, B$, and $C$ shown in Figure 9. Strain readings that were simultaneously recorded using the Adams data logger [33] during the loading and unloading sequence in the laboratory. See Figures 8 and 9.

The principal strains were determined using the strain transformation equations [35]. These were solved to determine the normal and shear strains, $\varepsilon_{x}, \varepsilon_{y}$ and $\gamma_{x y}$. From the generalised Hooke's law stress strain relationship equations, the normal and shear stresses, $\sigma_{\mathrm{x}}, \sigma_{\mathrm{y}}$ and $\tau_{\mathrm{xy}}$ were determined. The von Mises, $\sigma_{\mathrm{VM}, \mathrm{L}}$ stresses were determined using the principal stress values, $\sigma_{1}$ and $\sigma_{2}$ in:

$$
\sigma_{\mathrm{VM}, \mathrm{L}}=\left(\sigma_{1}{ }^{2}+\sigma_{2}{ }^{2}-\sigma_{1} \sigma_{2}\right)^{0.5}
$$

The typical strain values generated by the $8.0 \mathrm{kN}$ applied loading, at location vM1 shown in Table 5 and on the upper tube surface were recorded with $\{+v e\}$ and $\{$-ve $\}$ signs indicating tension and compression respectively. A spreadsheet was utilised to calculate the von Mises stresses for the 
laboratory recorded strain values, $\varepsilon_{a}, \varepsilon_{b}$, and $\varepsilon_{c}$ emanating from the rosette gauges $A, B$, and $C$ respectively due to the applied load increments.

The values used to determine the stresses shown in Table 5 were for Poisson's ratio, $v=0.3$, Elastic modulus, $\mathrm{E}=205 \mathrm{kN} / \mathrm{mm}^{2}$ and Shear modulus, $\mathrm{G}=78.85 \mathrm{kN} / \mathrm{mm}^{2}[2,19,24]$.

\subsection{Discussion of results}

It was evident that the assumed boundary support conditions in the GSA analysis models required the movement of the inclined legs to be determined. However, it was not possible to accurately measure lateral sliding displacement of the dome's inclined supports that were in contact with the web-stiffened steel beam flange plates in the laboratory experiment. This will be the subject of further study in future experimental investigations. The web-stiffened support beams rested on the concrete strong floor. These were levelled and connected together to prevent their movement. The possibility of out of plane support conditions was therefore not considered in the analysis.

The predicted and laboratory measured displacements and stresses are now considered and discussed.

\subsection{Displacements}

The predicted global displacement and deflected shape response of the eight GSA analysis models when loaded to the applied maximum $8 \mathrm{kN}$ are shown in Figures 12 and 13.

Model 1 in Figure 12 illustrates the global response assuming pinned boundary supports. It can be observed that an overall clockwise rotation of the structure is apparent, as highlighted by the blue lines, at boundary support level. An overall expansion in all directions emanating from the crown of the structure appears evident. As would be expected, a different deformed shape can be observed from models 2 and 3 with boundary support lateral movement evident. Model 4 has a similar appearance to model 1 . Models 5 to 8 are similar to models 1 to 4 but with the connections represented by springs. The predicted vertical displacement values, $\mathrm{Uz}$ are given in the Figures 12 and 13 captions for ease of comparisons.

The predicted and measured vertical displacements graphs for Uz1 and Uz2, and the Uz3 and Uz4 are illustrated in Figure 14 (a) and (b), and Figure 15 (a) and (b) respectively.

At the monitoring location Uz1 shown in Figure 6, analysis models 2, 3, 6, 7 and 8 all predicted higher displacement values than those measured in the laboratory. Model 5 was the nearest conservative predicted vertical displacement for loading up to and including $7 \mathrm{kN}$. At $8 \mathrm{kN}$, Uz1 $(5.801 \mathrm{~mm})$ value was $(-8.6 \%)$ below the laboratory measured $(5.929 \mathrm{~mm})$. Models 1 and 4 underestimated the Uz1 values. Model 4 was the nearest at $(-27.3 \%)$ below the analysis predicted value of $(4.311 \mathrm{~mm})$ compared to the laboratory measured value.

At Uz2, analysis models 2 to 8 all predicted higher displacement values than those measured in the laboratory. Model 4 was the nearest conservative predicted vertical displacement, Uz2 $(5.301 \mathrm{~mm})$ value that was $(+1.2 \%)$ above the laboratory measured $(5.236 \mathrm{~mm})$. Model 1 , underestimated the Uz2 values and was the nearest at $(-33.3 \%)$ below the analysis predicted value of $(3.494 \mathrm{~mm})$ compared to the laboratory measured value.

Analysis models 2, 6 and 7 predicted higher displacement values at Uz3 than those measured in the laboratory. Model 8 was the nearest conservative predicted vertical displacement, Uz3 $(6.453 \mathrm{~mm})$ 
value that was $(-7.7 \%)$ below the laboratory measured $(6.992 \mathrm{~mm})$. Models $1,3,4$, and 5 underestimated the Uz3 values. Model 3 was the nearest at $(-23.5 \%)$ below the analysis predicted value of $(5.349 \mathrm{~mm})$ compared to the laboratory measured value of $(6.992 \mathrm{~mm})$.

At Uz4, analysis models 2 and 6 both predicted higher displacement values than those measured in the laboratory. Model 7 was the nearest conservative predicted vertical displacement, Uz4 (3.496 $\mathrm{mm}$ ) value that was $(-0.2 \%)$ below the laboratory measured $(3.502 \mathrm{~mm})$. Models $1,3,4,5$ and 8 underestimated the Uz4 values. Model 3 was the nearest at $(-15.9 \%)$ below the analysis predicted value of $(2.946 \mathrm{~mm})$ compared to the laboratory measured value.

It was anticipated that the less stiff analysis models would predict the higher displacements. The lower predicted displacements at Uz1 are given by models 1 and 4 respectively. In model 1, the boundary supports are all pinned with the connections fully fixed. Model 1 was the stiffest of all of the analysis models. At $8 \mathrm{kN}$ loading, the lowest predicted displacement $(2.451 \mathrm{~mm})$ was $(-58.7 \%)$ lower than the displacement measured in the laboratory $(5.929 \mathrm{~mm})$. In model 4, all the boundary supports have spring stiffnesses with the connections being fully fixed. Above $3 \mathrm{kN}$ loading, model 4 predicted displacements lower than those measured in the laboratory. At $8 \mathrm{kN}$ loading, the lower predicted displacement $(4.311 \mathrm{~mm})$ was $(-27.3 \%)$ lower than the displacement measured in the laboratory $(5.929 \mathrm{~mm})$.

The lowest predicted displacements at Uz2 are given by model 1 being the stiffest of all of the analysis models. Above $3 \mathrm{kN}$ loading, model 1 predicted displacements lower than those measured in the laboratory. At $8 \mathrm{kN}$ loading, the lower predicted displacement $(3.494 \mathrm{~mm})$ was $(-33.3 \%)$ lower than the displacement measured in the laboratory $(5.236 \mathrm{~mm})$.

The lower predicted displacements at Uz3 are predominately given by models $1,3,4$ and 5 . Table 4 shows the analysis assumptions regarding the boundary and connection conditions. In order of stiffness, model 1 is the stiffest, followed by models 4,5 , and 3 . These models all underestimated the measured displacements. At $8 \mathrm{kN}$ loading, the model 1 lower predicted displacement $(1.888 \mathrm{~mm})$ was (-73.0\%) lower than the displacement measured in the laboratory $(6.992 \mathrm{~mm})$; model $4(3.67$ $\mathrm{mm}$ ) was $(-47.5 \%)$ lower; model $5(4.769 \mathrm{~mm})$ was $(-31.8 \%)$ lower and model $3(5.349 \mathrm{~mm})$ was ($23.5 \%)$ lower than the displacement measured in the laboratory.

The lower predicted displacements at Uz4 were predominately given by models $1,3,4,5$ and 8 . Model 1 was the stiffest, followed by models $5,4,8$, and 3 . These models all underestimate the measured displacements above $3 \mathrm{kN}$ for model $4 ; 4 \mathrm{kN}$ for model 8 , and $5 \mathrm{kN}$ for model 3 respectively. At $8 \mathrm{kN}$ loading, the model 1 lower predicted displacement $(0.541 \mathrm{~mm})$ was $(-84.6 \%)$ lower than the displacement measured in the laboratory $(3.502 \mathrm{~mm})$; model $5(1.413 \mathrm{~mm})$ was ($59.7 \%)$ lower; model $4(1.841 \mathrm{~mm})$ was $(-47.4 \%)$ lower, model $8(2.586 \mathrm{~mm})$ was $(-26.2 \%)$ lower and model $3(2.946 \mathrm{~mm})$ was $(-15.59$ lower than the displacement measured in the laboratory.

\section{2 von Mises stress}

The predicted global von Mises stresses response of the eight GSA analysis models considered are shown in Figures 16 and 17.

The maximum predicted von Mises stresses values are given in the Figures 16 and 17 captions for ease of comparisons.

In Figure 16, GSA models 1 to 4 typically predict that the material yield stress is exceeded in the bolted connections at various locations. Model 1 shows these in one or more of the connections in 
circuits ( $C 1$ to $\mathrm{C} 3$ ), (C5 to $\mathrm{C} 9$ ), $\mathrm{C} 12, \mathrm{C} 14, \mathrm{C} 15$ and $\mathrm{C} 17$. See Figure 6 for module circuit numbering. Model 2 indicates that the material yield stress is exceeded in one or more of the connections in circuits ( $\mathrm{C} 1$ to $\mathrm{C} 3$ ), ( $\mathrm{C} 5$ to $\mathrm{C} 18$ ) and $\mathrm{C} 20$. Model 3 predicts that the material yield stress is exceeded in module circuits ( $\mathrm{C} 1$ to $\mathrm{C} 3$ ), (C5 to $\mathrm{C} 10), \mathrm{C} 14$ and C18. Model 4 predicts circuits ( $\mathrm{C} 1$ to $\mathrm{C} 3$ ), (C5 to $\mathrm{C} 10)$, C12 and (C14 to C19).

The analysis models 1 to 4 indicated that the least likely RSE modules circuits where the onset of local yielding would occur were, (C10, C12, C15, C17 and C18) followed by (C16) followed by (C11, $\mathrm{C} 13, \mathrm{C} 19$ and $\mathrm{C20}$ ) respectively, with all models predicting that $\mathrm{C} 4$ would be the last circuit to show any signs of yielding. It is anticipated that this will be the subject of a future nonlinear response study.

In Figure 17, GSA models 5 to 8 predict that the material yield stress is not exceeded at any location under the applied maximum loading of $8 \mathrm{kN}$.

The predicted and the laboratory determined von Mises stresses graphs at the monitored locations, vM1, vM2 and vM3 are illustrated in Figure 18 (a), (b) and (c).

At the monitoring location vM1 shown in Figure 6, analysis model 5 predicted a von Mises stress $\left(34.8 \mathrm{~N} / \mathrm{mm}^{2}\right)$ value that was $(+0.6 \%)$ above the laboratory determined von Mises stress (34.6 $\mathrm{N} / \mathrm{mm}^{2}$ ). Models 1 and 4 underestimated the predicted von Mises stress at that point. Model 4 was the nearest at $(-18.8 \%)$ below the analysis predicted value of $\left(28.1 \mathrm{~N} / \mathrm{mm}^{2}\right)$ compared to the laboratory determined value.

At $\mathrm{VM} 2$, analysis model 5 predicted a von Mises stress $\left(20.2 \mathrm{~N} / \mathrm{mm}^{2}\right)$ value that was $(+6.3 \%)$ above the laboratory determined von Mises stress of $\left(19.0 \mathrm{~N} / \mathrm{mm}^{2}\right)$. Models 1 and 4 underestimated the predicted von Mises stress at that point. Model 4 was the nearest at $(-13.7 \%)$ below the analysis predicted value of $\left(16.4 \mathrm{~N} / \mathrm{mm}^{2}\right)$ compared to the laboratory determined value.

Analysis model 7 at the monitoring location $\mathrm{vM} 3$, predicted a von Mises stress value of $\left(34.8 \mathrm{~N} / \mathrm{mm}^{2}\right)$ that was $(+37.6 \%)$ above the laboratory determined von Mises stress of $\left(25.3 \mathrm{~N} / \mathrm{mm}^{2}\right)$. Models 1,4 , 5 and 8 underestimated the predicted von Mises stress at that point. Model 8 was the nearest at ($17.0 \%)$ below the analysis predicted value of $\left(21.0 \mathrm{~N} / \mathrm{mm}^{2}\right)$ compared to the laboratory determined value.

The lower predicted von Mises stresses at both locations VM1 and VM2, shown in Figure 6, are given by both models 1 and 4 . At vM1 under $8 \mathrm{kN}$ loading, model 1 predicted $\left(20.7 \mathrm{~N} / \mathrm{mm}^{2}\right)$ that was ($40.2 \%)$ lower; and model 4 predicted $\left(28.1 \mathrm{~N} / \mathrm{mm}^{2}\right)$ that was $(-18.8 \%)$ lower than the von Mises stresses laboratory determined values of $\left(34.6 \mathrm{~N} / \mathrm{mm}^{2}\right)$ at $\mathrm{vM} 1$, and $\left(19.0 \mathrm{~N} / \mathrm{mm}^{2}\right)$ at $\mathrm{vM} 2$. The lower predicted von Mises stresses at vM3 were given by models 1, 4, 5 and 8 . At $8 \mathrm{kN}$ loading, the model 1 lower predicted von Mises stress $\left(10.9 \mathrm{~N} / \mathrm{mm}^{2}\right)$ was $(-56.9 \%)$ lower than the von Mises stress laboratory determined value of $\left(25.3 \mathrm{~N} / \mathrm{mm}^{2}\right)$; model 5 was $(-45.8 \%)$ lower at $\left(13.7 \mathrm{~N} / \mathrm{mm}^{2}\right)$; model 4 was $(-23.3 \%)$ lower at $\left(19.4 \mathrm{~N} / \mathrm{mm}^{2}\right)$ and model 8 was $(-17.0 \%)$ lower at $\left(21.0 \mathrm{~N} / \mathrm{mm}^{2}\right)$.

\subsection{Conclusions}

To replicate the anticipated support conditions in the laboratory a number of factors were investigated. Eight global linear elastic analysis models with variations in boundary supports in combination with two types of connection models were considered. 
Modelling of the anticipated boundary support conditions to determine lateral stiffnesses, potential for sliding under load, CHS bolted connection lateral and rotational stiffnesses, required analysis in stages to be carried out. The creation of finite element connection models and CHS ring models of varying widths, with and without clearance holes, were required to determine the averaged spring and equivalent stiffnesses used in the dome global analysis models.

The experiment confirmed that the leg support spring stiffnesses, expected to have a direct effect on the displacement and distribution of stress, was complex to monitor. This was due to the out-ofplane nature of the displacements containing $U x, U y$ and $U z$ axes components.

The GSA analysis models used two connection model types to represent the twelve RSE bolted connection present in each of the five dome sectors. Connection model 1 used a fully fixed beam element. Connection model 2 used separate translational and rotational spring elements. The target eccentricity and the averaged orientation angle of 60 degrees were used to determine the equivalent stiffnesses for the spring elements.

Models 4 and 5 provide the most accurate displacement predictions at location Uz1; models 1 and 4 at location Uz2; models 3 and 8 at Uz3 and models 3 and 7 at location Uz4. Model 1 was the stiffest model in terms for boundary and connection assumptions and predicted the lowest displacements at all of the monitored locations. The least stiff analysis Model 6 predicted the highest displacements at the monitored locations.

Unrepresentative high values of Von Mises stresses were apparent when beam elements representing the bolted connections were assumed to have full fixity between the CHS tubes. When two GSA translational and rotational spring elements were used to represent the connections, smaller stresses were developed in the bolts.

Model 5 was the most accurate at predicting the von Mises stresses to those monitored in the laboratory at locations vM1 and vM2. Model 8 was the closest at predicting the von Mises stresses to those monitored in the laboratory at location vM3. These however were below those monitored. The lower predicted von Mises stresses at locations VM1 and VM2 are given by models 1 and 4, and at vM3 are given by models $1,4,5$ and 8 .

For this study, a number of analysis models accurately predicted the displacements and the von Mises stresses for a specific load range only at the monitored locations. The plotted laboratory results were found to intersect a number of analysis models predictions. Consequently, not one of the analysis models alone could be identified as providing the most accurate predictions.

Each of the twelve connection types evident in the five dome sectors had different relative orientations. Using the target eccentricity and an averaged orientation value of 60 degrees for each joint resulted in some accurate predictions for the displacements and Von Mises stresses at the monitored locations. These may be improved further by using the target eccentricity and the individual orientation angles occurring at each joint in order to obtain the most representative equivalent stiffnesses required for analysis modelling.

The applied loading was within the elastic range of the tube material according to the Von Mises yield criterion and the behaviour of the dome remained elastic.

Many factors could have contributed to the differences in the recorded measured strains. These may include (i) the variations in material properties due to the manufacturing process, (ii) slight variation in the rosette strain gauge locations bonded to the upper CHS surfaces, (iii) the load distribution 
applied via the load transfer beam and bearing assembly alignments, and (iv) the final accuracy of the constructed dome resulting from the individually manufactured tube elements assembly.

\section{Acknowledgements}

The author would like to express his thanks to Tony Stevens, Bruce Hassan and Armstrong Briscoe for the manufacture, construction and setting up the test rig, installing the instrumentation, carrying out the loading and recording the results for the tests.

\section{References}

[1] Nooshin, H. and Disney, P., Formex configuration processing II. International Journal of Space Structures, 16 (1), pp 1 - 56, 2001.

[2] Rizzuto, J.P., The structural behaviour of mutually supported elements in space structures, PhD thesis, Coventry University, 2005.

[3] Popovic, O. Reciprocal Frame Structures. PhD thesis, University of Nottingham, 1996.

[4] Baverel, O. Nexorades: A family of interwoven space structures. PhD thesis University of Surrey, 2000.

[5] Popovic-Larsen, O. Reciprocal Frame Architecture. Routledge, 2008.

[6] Pugnale, A. and Sassone, M. Structural Reciprocity: Critical Overview and promising research/design issues. Nexus Network Journal, 16 (1), pp9-35, 2014.

[7] Rizzuto, J.P., Saidani, M. and Chilton, J. C. Polyhedric Space Structures Using Reciprocally Supported Elements of Various Cross-Sections, Journal of The International Association for Shell and Spatial Structures 42 (3) (137) December, pp. 149-159, ISSN: 0304 3622, 2001.

[8] Rizzuto, J.P., Saidani, M. and Chilton, J. C. Proc. fifth Int. Conference on Space Structures, Edited by GAR Parke and P Disney, Multi-Reciprocal Element (MRE) Space Structure Systems, University of Surrey, UK, August, pp 641-649, Thomas Telford Ltd, ISBN: 07277 31734, 2002.

[9] Rizzuto, J.P. and Chilton, J. C. Proc. Int. Symp. on New Perspectives for Shell and Spatial Structures: Extended Abstracts, Mutually Supported Cylindrical Elements, Taipei, Taiwan, The International Association for Shell and Spatial Structures. pp 42-43, ISBN: 986 8022222, 2003.

[10] Rizzuto, J.P. Proc. Second Int. Conference on Structural Engineering, Mechanics and Computation: Extended Abstracts, Edited by A Zingoni, Mutually Supported Elements (MSE) in Space Structures, University of Cape Town, South Africa, July, pp 71, AA Balkema, Taylor \& Francis Group plc, ISBN: 905809 5681, ISBN CD-ROM 905809 698X, 2004.

[11] Pizzagoni, A. Leonardo and the reciprocal structures. Bergamo, Tecnograph, 2010.

[12] B. Sénéchal, C. Douthe, O. Baverel. Analytical investigations on elementary nexorades. International Journal of space Structure, 26 (4), pp. 314-320, 2011.

[13] Song, P., Fu, C., Goswami, P., Zheng, J., Mitra, N., and Cohen-Or, D. Reciprocal Frame Structures Made Easy. ACM Transactions on Graphics (TOG), 32 (4), 2013. 
[14] Anastas, Y., Rhode-Barbarigos, L. and Adrianenssens, S. Design-to-construction workflow for cellbased pattern reciprocal free-form structures, Journal of The International Association for Shell and Spatial Structures 57 (2) (188) June, pp. 159-176, ISSN: 0304 3622, 2016.

[15] Corio, E., Laccone, F., Pietroni, N., Cignoni, P. and Froli, M. Conception and parametric design workflow for a timber large-spanned reversible grid shell to shelter the archaeological site of the Roman shipwrecks in Pisa. International Journal of Computational Methods and Experimental Measurements. WIT Press. 5 (4), pp 551 - 561. ISSN: 2046-0546 \& ISSN: 2046-0554 (online). Selected Wessex MARAS paper, 2017.

[16] Rokko Mountain Observatory, Kobe, Japan. The Arup Journal, (1), pp 20 - 26, 2011.

[17] Nooshin, H. and Disney, P., Formex configuration processing I. International Journal of Space Structures, 15 (1), pp 1 - 52, 2000.

[18] Saidani, M., and Rizzuto, J.P. Proc. Int. Symp. on Shell and Spatial Structures from Models to Realization: Extended Abstracts, Edited by R Motro, Structural Behaviour of Square Grids with Mutually Supported Elements under Static Loading, University of Montpellier II, France, September, pp 192, ISBN: 291226122 8, 2004.

[19] Rizzuto, J.P. and Hulse, R. Dodecahedric Mutually Supported Element Space Structure: Experimental Investigation. International Journal of Space Structures. 22 (2), pp 107 - 121, ISSN: 0266 3511, 2007.

[20] Rizzuto, J.P. Proc. IASS Symposium/Conference on Evolution and Trends in Design, Analysis and Construction of Shell And Spatial Structures: Extended Abstracts, Dodecahedric Mutually Supported Element Space Structure Experimental and Numerical Modelling Investigation: Discussion of Results. Valencia, Spain, September, pp 440 - 441. ISBN 978848363459 2, 2009.

[21] Rizzuto, J.P. Rotated Mutually Supported Elements in Truncated Icosahedric Domes. Journal of the International Association for Shell and Spatial Structures 48 (1), (153), April, pp $3-17$, ISSN: 0304-3622, 2007.

[22] Rizzuto, J.P. Dodecahedric Mutually Supported Element Space Structure: Numerical Modelling. Journal of the International Association for Shell and Spatial Structures. 49 (1), (157), April, pp 3 - 18 ISSN: $1028-365 X, 2008$.

[23] Rhinoceros Training Manual v.4.0, Robert McNeal \& Associates, 2006.

[24] OASYS GSA Help Guide, GSA 8.7, London, England, 2016.

[25] Rizzuto, J.P. Structural modelling investigation of reciprocally supported element lattice honeycomb domes. International Journal of Computational Methods and Experimental Measurements. WIT Press. 5 (4), pp 432 - 441. ISSN: 2046-0546 \& ISSN: 2046-0554 (online). Selected Wessex MARAS paper, 2017.

[26] Rizzuto, J.P., Saidani, M. and Chilton, J. C. Proc. Int. Symp. on Theory, Design and Realization of Shell and Spatial Structures, Extended Abstracts. Joints and Orientation of Module Elements in MultiReciprocal Grid (MRG) Systems, Nagoya, Japan, The International Association for Shell and Spatial Structures. pp. 308-309, 2001. 
[27] Rizzuto, J.P. and Popovic-Larsen, O. Connection systems in reciprocal frames and mutually supported elements space structure networks. International Journal of Space Structures. 25 (4), pp 243 - 256. ISSN: 0266 3511, 2010.

[28] Rizzuto, J.P. Eccentricity orientation of bolted connections in mutually supported element platonic polyhedral configurations. Journal of the International Association for Shell and Spatial Structures. 55 (1), pp 49 -62, ISSN: 1028 365X, 2014.

[29] BS EN 1993-1-8: 2005: Eurocode 3: Design of steel structures - Part 1-8: Design of joints. London: BSI, 2005.

[30] BS EN 1993-1-1: 2005: Eurocode 3: Design of steel structures - Part 1-1: General rules and rules for buildings. London: BSI, 2005.

[31] Micro-Measurements, Vishay Precision Group, WA-06-250WR-350. Available at: http://www.vishaypg.com. (Accessed: 20 August 2017.)

[32] Demec Mechanical Strain Gauges. Available at: http://www.mastrad.com/demecsg.htm. (Accessed: 20 August 2017.)

[33] Adams Data Logger. Available at: http://www.advantech.com. (Accessed: 20 August 2017.)

[34] Linear Variable Differential Transformers (LVDTs), displacement measurement sensors. Available at: http://www.rdpe.com/displacement/lvdt.htm. (Accessed: 20 August 2017.)

[35] Hannah, J and Hillier, M. J. Applied Mechanics, 3rd Edition, Longman Scientific \& Technical, 1995. 


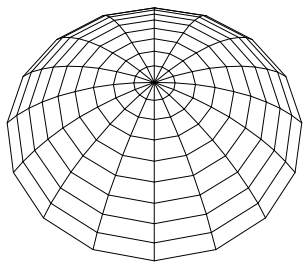

(a)

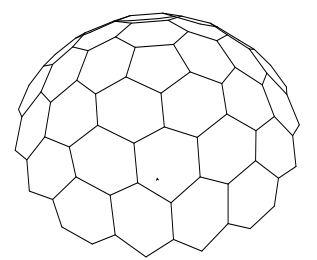

(d)

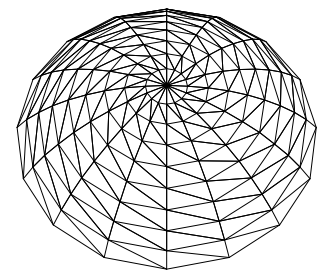

(b)

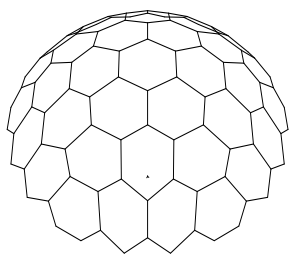

(e)

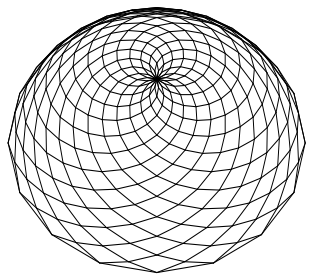

(c)

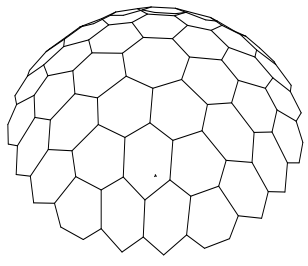

(f)

Figure 1: Dome families with potential element cluttering near crown: (a) Ribbed, (b) Schwedler, (c) Lamella domes. Formian generated Diamatic Honeycomb pattern domes with frequency, $m=3$, sweep angle, (rise) $A=60$ degrees and, (d) number of sectors, $n=5,(e) n=6$ and (f) $n=7$.

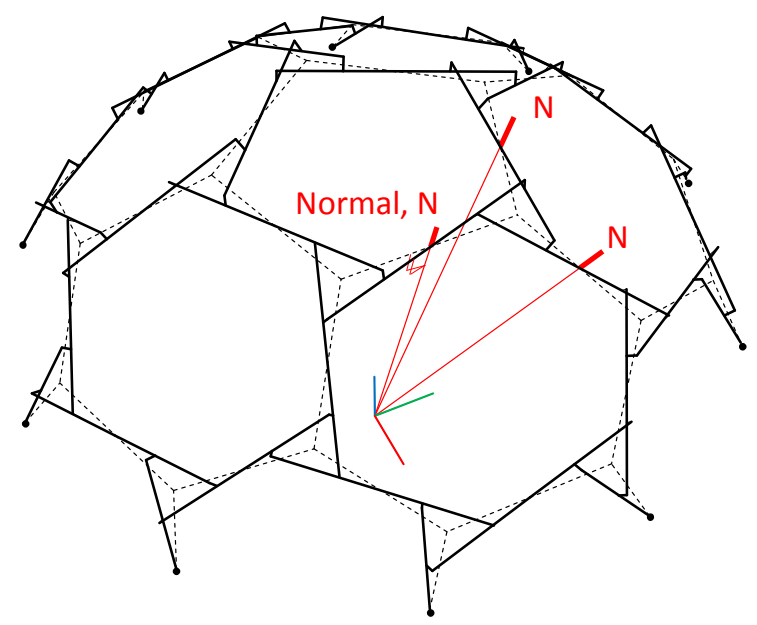

Figure 2: Perspective views of RSE honeycomb basic dome (dotted) and rotation method transformation using initial rotation angle of 15 degrees (one apex conversion shown only) about normal, $\mathrm{N}$. 


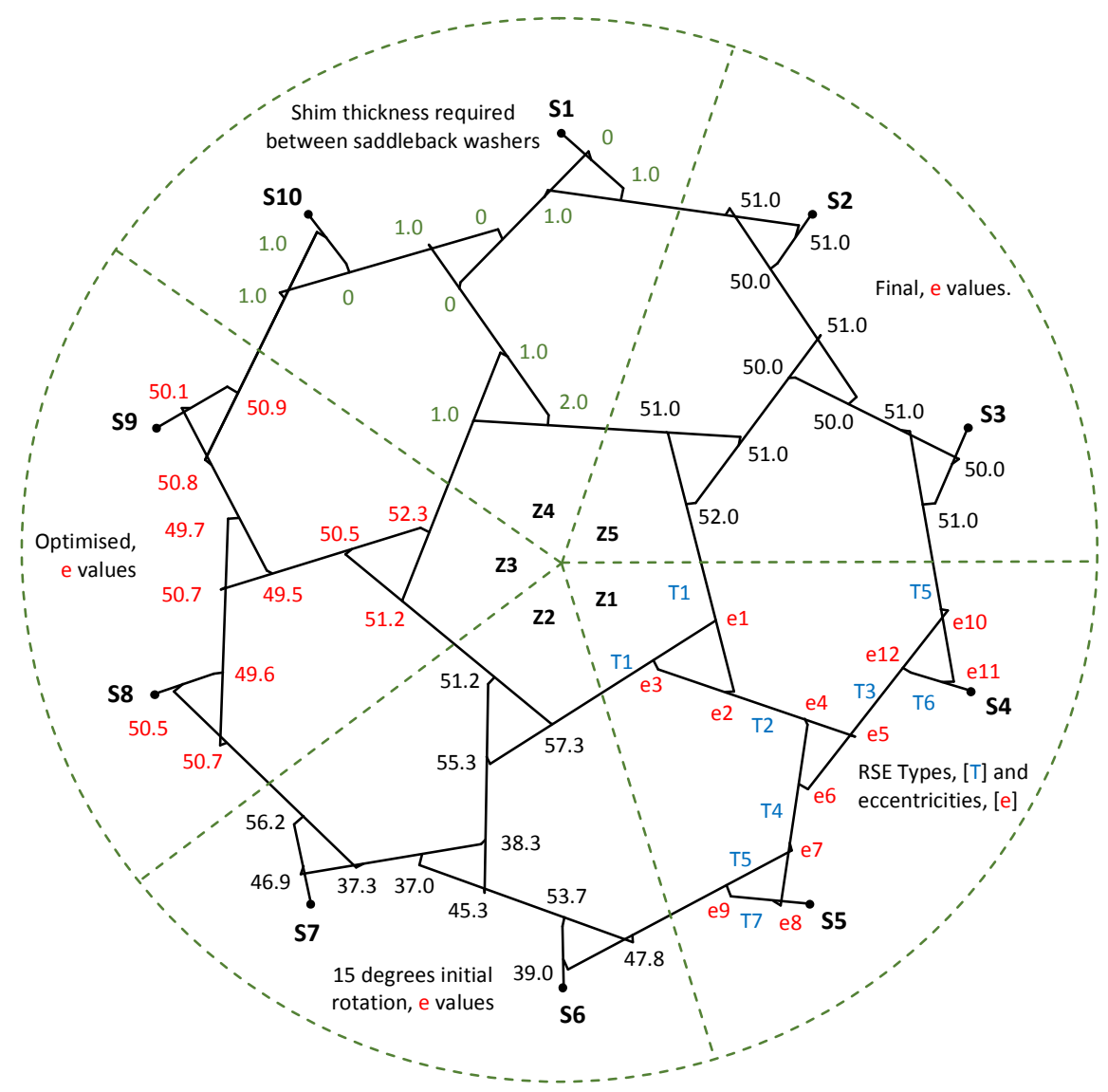

Figure 3: RSE Honeycomb dome plan showing boundary supports, [S1 - S10]. Elements types, [T1 - T7] and bolted connections eccentricity, [e1 - e12] locations and values. Note: all sector zones [Z1 - Z5] identical with symmetry indicated by dotted lines.

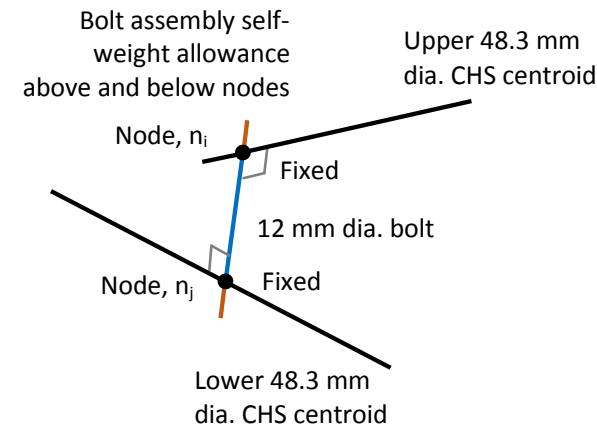

(a) Connection model type 1

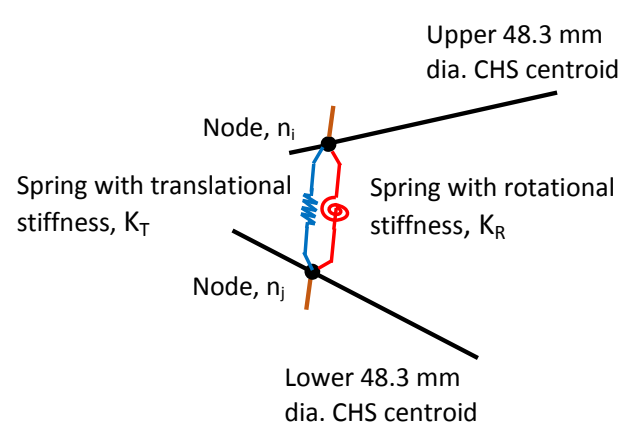

(b) Connection model type 2

Figure 4: RSE connections modelled in GSA analysis. 

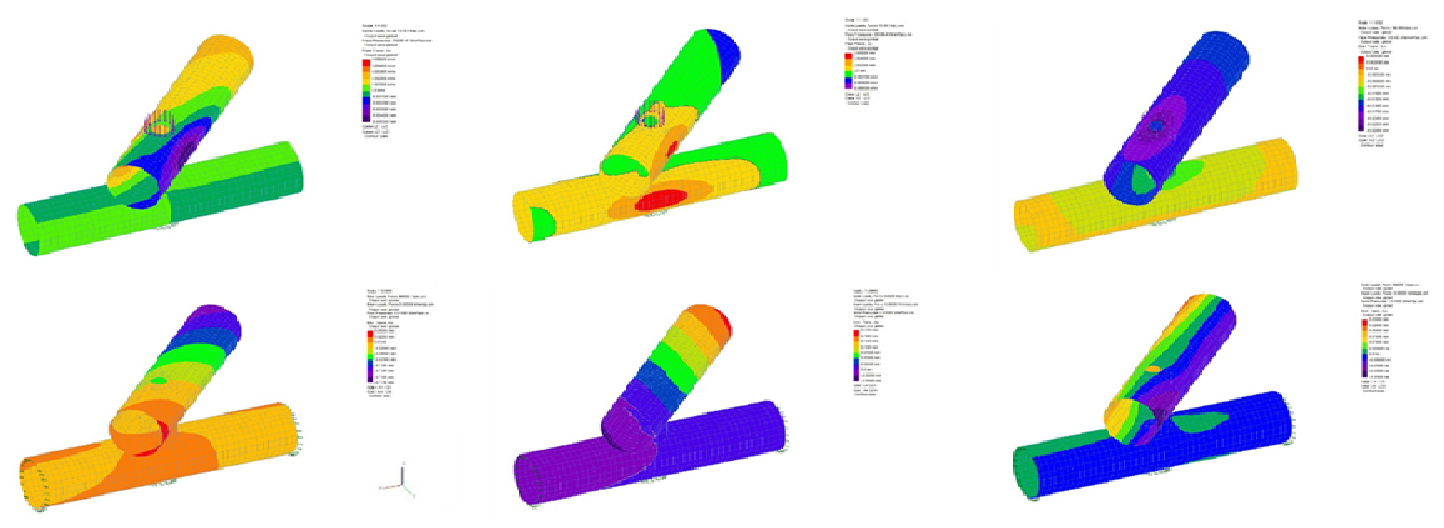

Figure 5: Refined second stage FEA connection model used to determine translational, $\mathrm{k}_{\mathrm{T}}$ and rotational, $k_{R}$ spring stiffness values for GSA analysis connection model 2 . The upper three FEA outputs (from $L$ to $R$ ) illustrate axial displacement components in the $x, y$ and $z$ axis direction. The lower three FEA outputs (from $L$ to $R$ ) illustrate moment components in the $x, y$ and $z$ axis direction displacements.

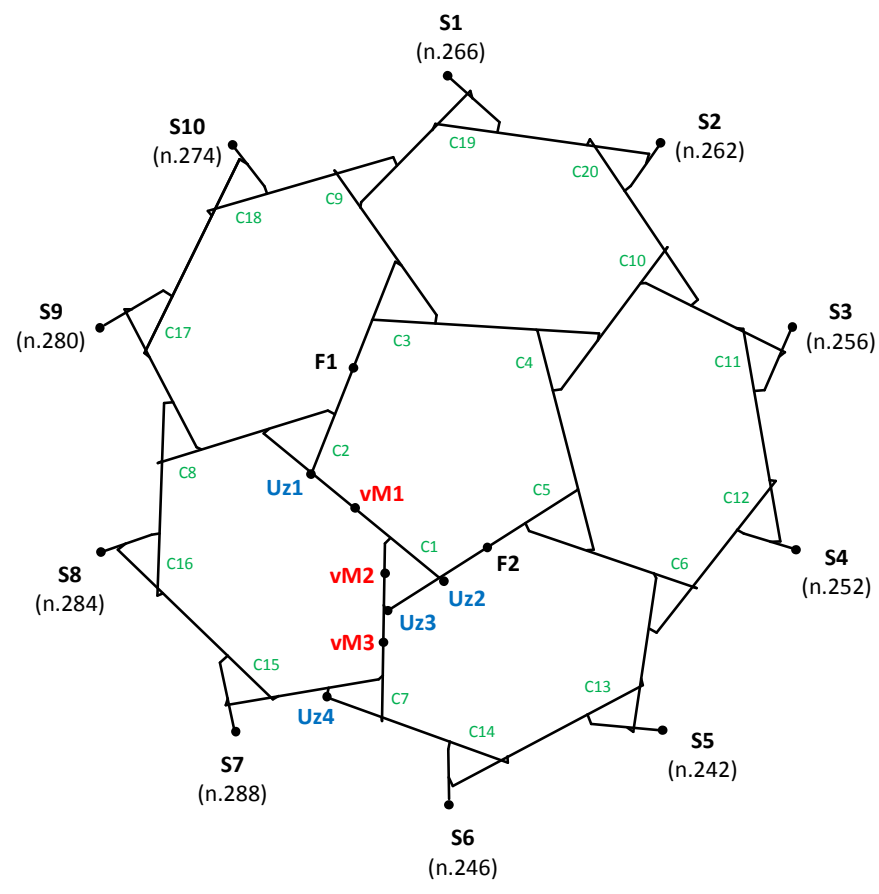

Figure 6: RSE Honeycomb dome plan with GSA analysis boundary supports node numbering. Loading positions indicated by [F1 - F2], displacement monitoring, [Uz1 - Uz4] and GSA analysis and lab von Mises stresses monitoring locations, [vM1 - vM3]. Module circuits numbered [C1 - C20]. 


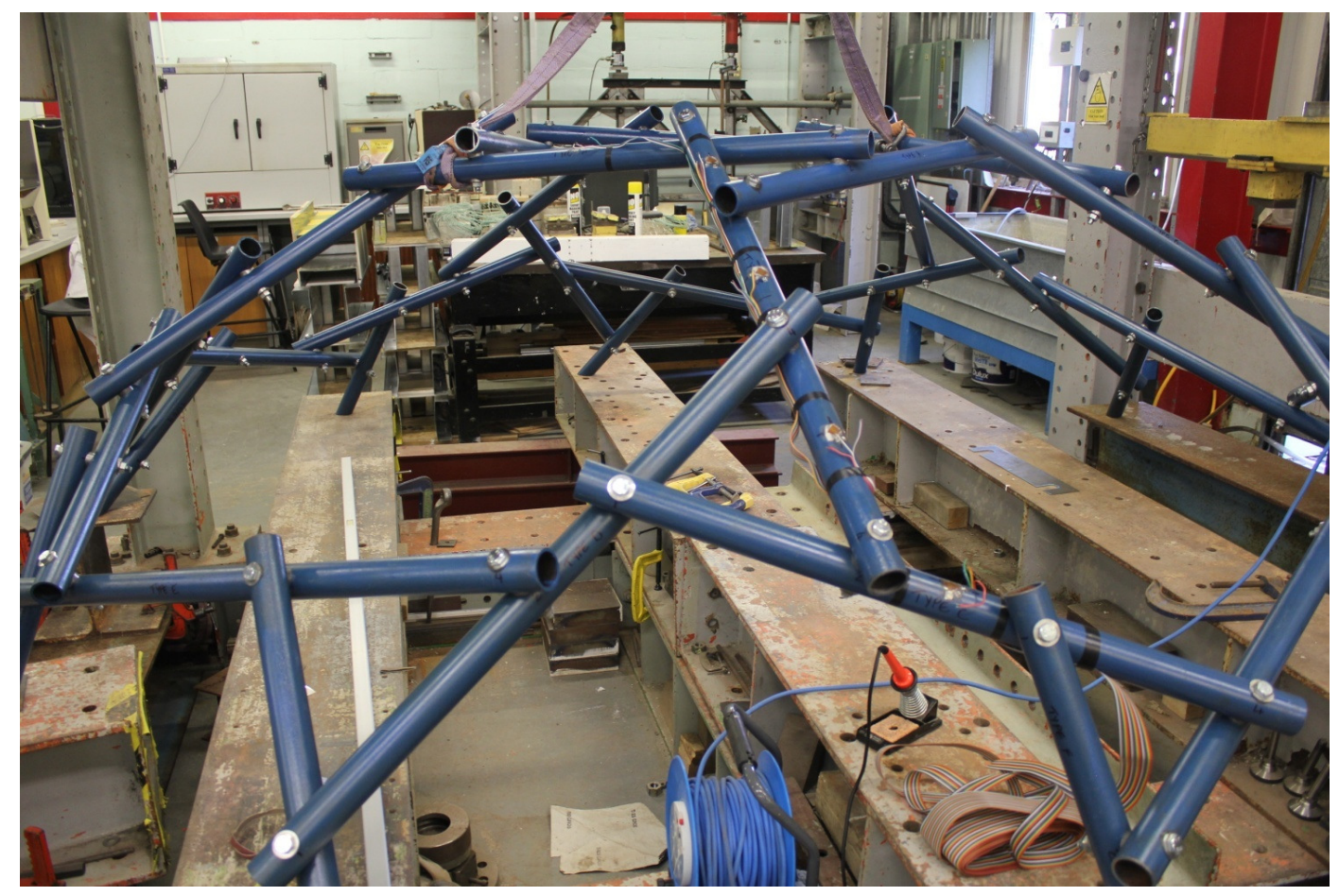

Figure 7: Honeycomb dome being constructed in the laboratory.

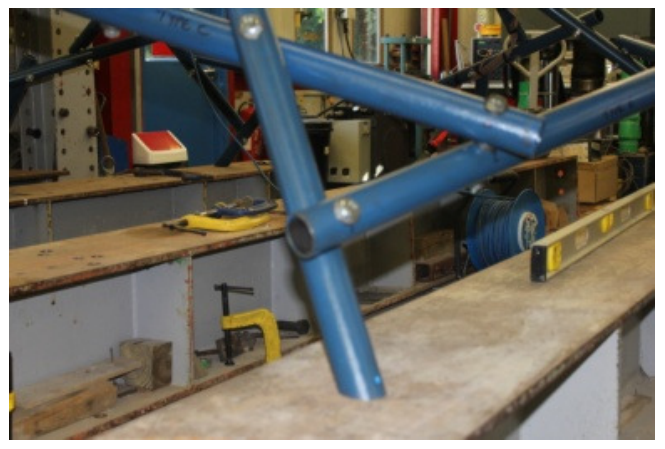

(a)

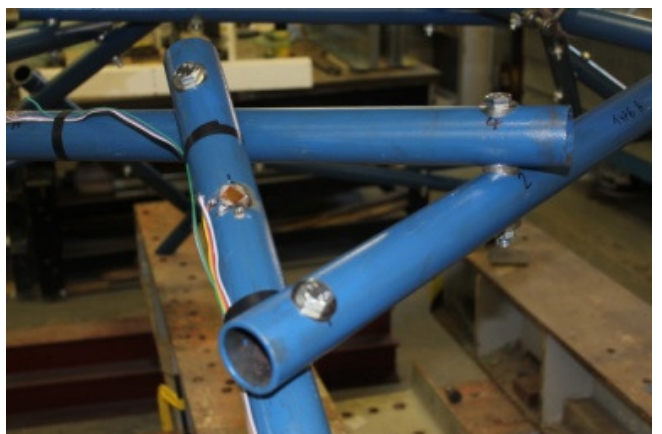

(b)

Figure 8: (a) Boundary leg support detail (b) bolted connections and bonded rosette strain gauges detail on tube upper surface.

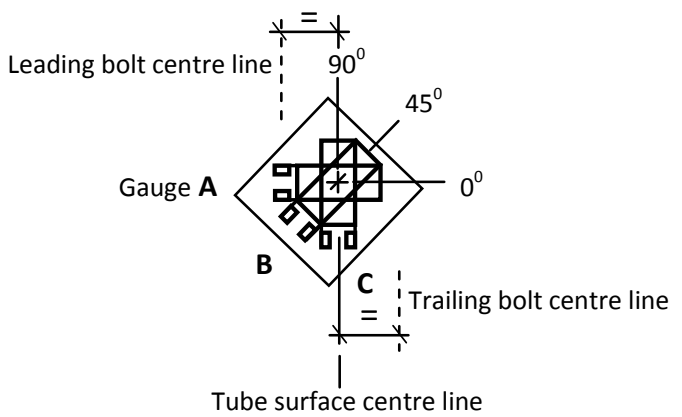

Figure 9: Rosette stacked strain gauge matrix orientation on upper tube surfaces (not to scale). See Figure 8 (b) and Figure 4 for monitoring locations. 


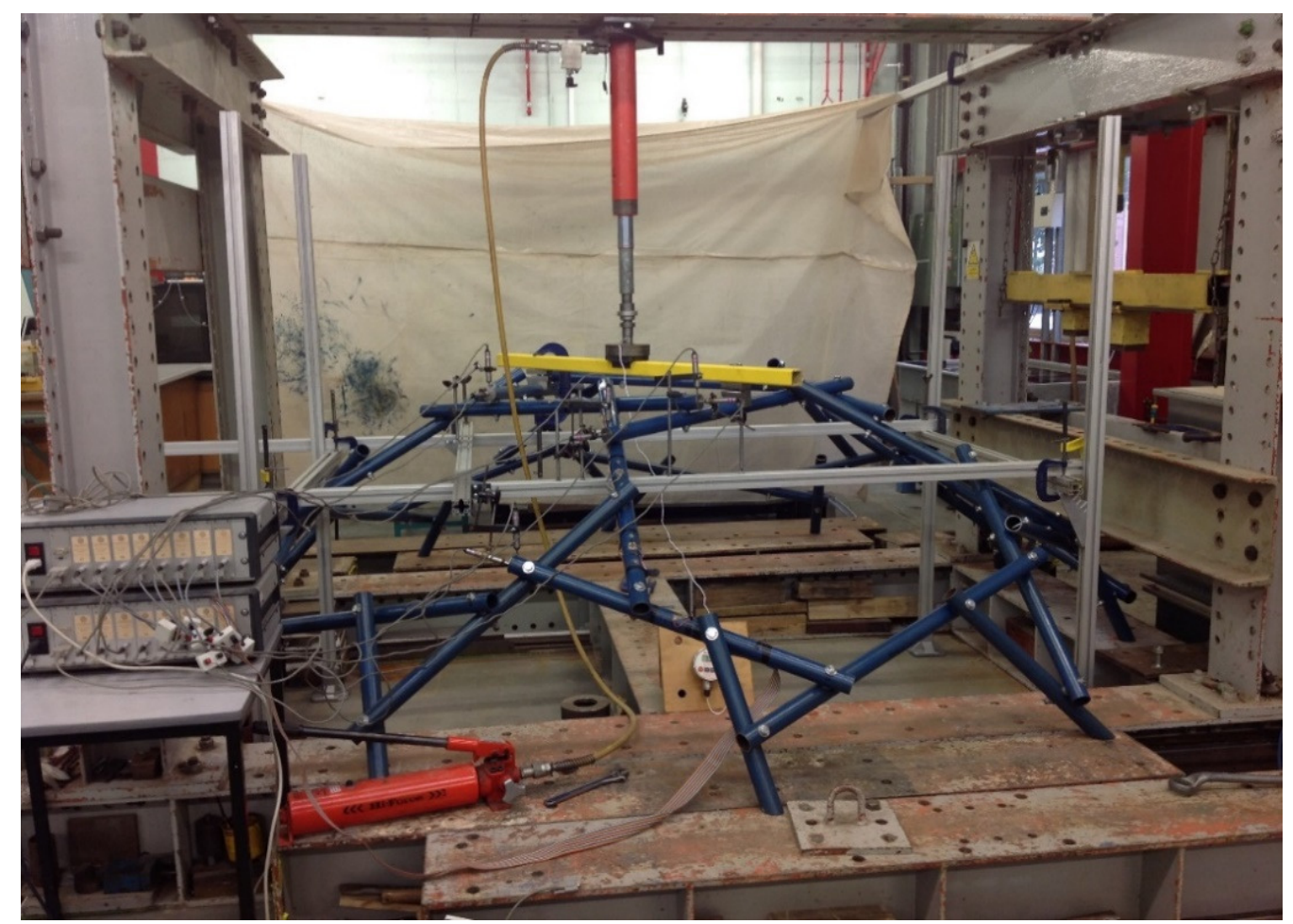

Figure 10: RSE honeycomb dome in test setup.

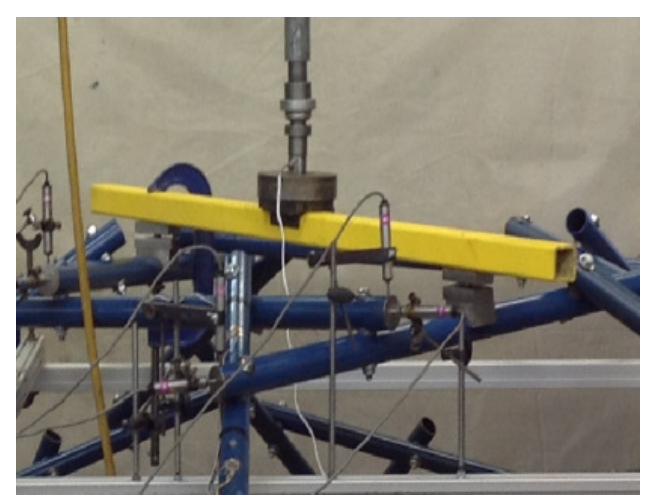

(a)

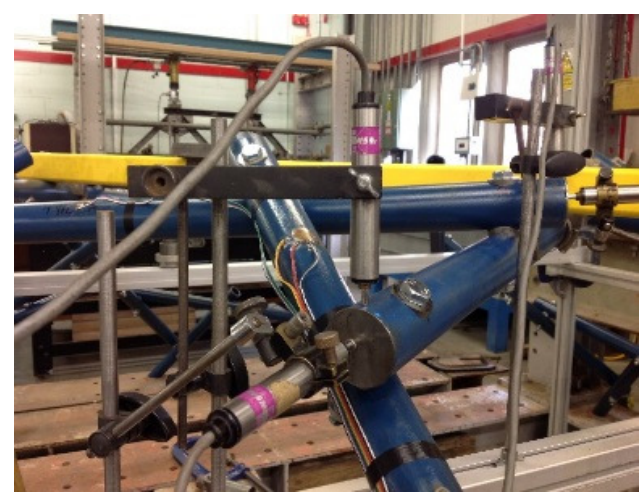

(b)

Figure 11: (a) Hydraulic ram loading spreader beam and tube bearing assembly (b) LVDT set up detail at Uz2 and Uz3 (foreground) displacement monitoring locations. 

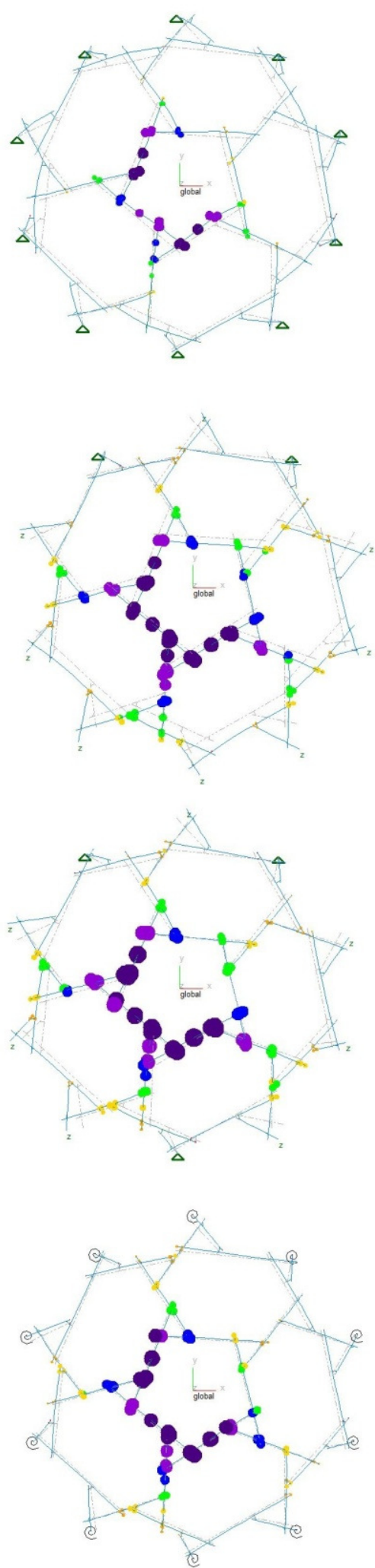

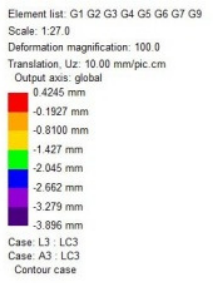

(Model 1) All supports pinned. All connections fixed.

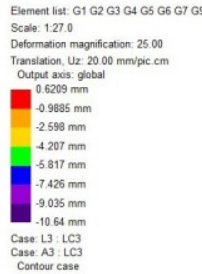

(Model 2) Two supports pinned (triangles) remainder on rollers. All connections fixed.
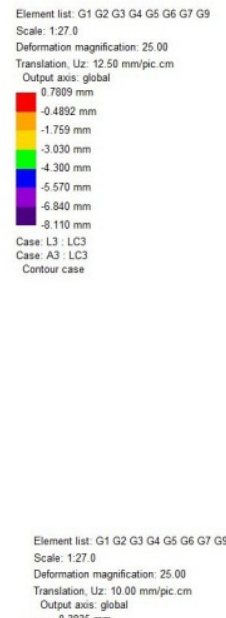

$-0.426 \mathrm{~mm}$

$-1.349 \mathrm{~mm}$
$-2.215 \mathrm{~mm}$
$-3.081 \mathrm{~mm}$

$-3.081 \mathrm{~mm}$
$-3.947 \mathrm{~mm}$
$-4.13 \mathrm{~mm}$

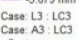

(Model 3) Three supports pinned (triangles) remainder on rollers. All connections fixed.

(Model 4) Supports all with spring stiffnesses. All connections fixed.

Figure 12: GSA analysis models [1 to 4] predicted displacements and deflected shapes at $8 \mathrm{kN}$ max applied loading. Max vertical Uz (dark purple): Model 1: $-3.896 \mathrm{~mm}$, Model 2: $-10.640 \mathrm{~mm}$, Model 3: $-8.110 \mathrm{~mm}$ and Model 4: $-5.679 \mathrm{~mm}$. See Table 4 for full details of boundary support and CHS connection conditions. 


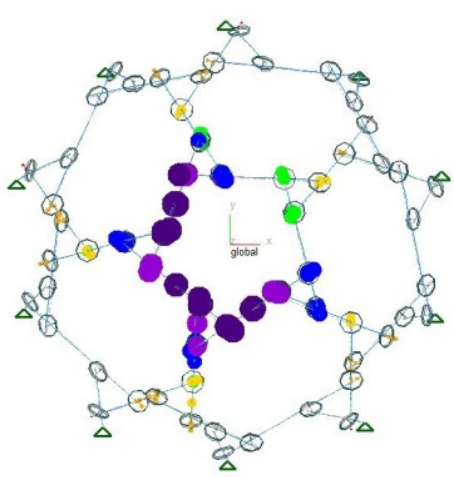

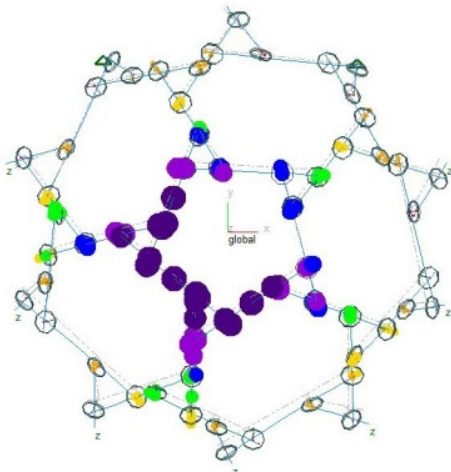

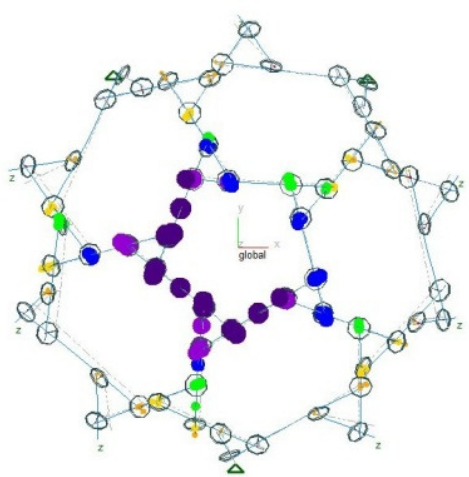

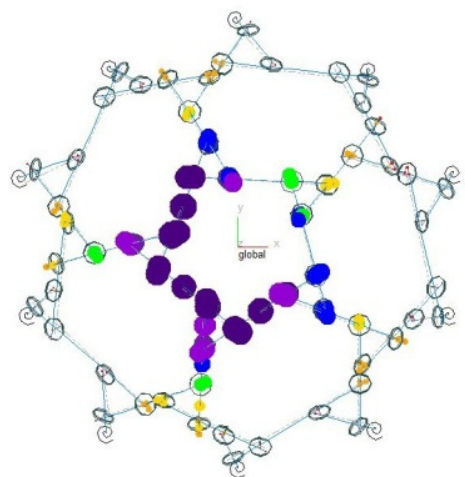

(Model 5) All supports pinned. All connections with spring stiffnesses.

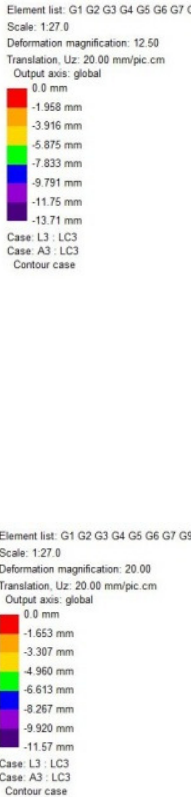

(Model 6) Two supports pinned (triangles) remainder on rollers. All connections with spring stiffnesses.

(Model 7) Three supports pinned (triangles) remainder on rollers. All connections with spring stiffnesses.

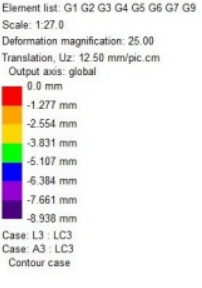

(Model 8) Supports all with spring stiffnesses. All connections with spring stiffnesses.

Figure 13: GSA analysis models [5 to 8] predicted displacements and deflected shapes at $8 \mathrm{kN}$ max applied loading. Max vertical Uz (dark purple): Model 5: -7.101 mm, Model 6: $-13.710 \mathrm{~mm}$, Model 7:

$-11.570 \mathrm{~mm}$ and Model 8: $-8.938 \mathrm{~mm}$. See Table 4 for full details of boundary support and CHS connection conditions. 


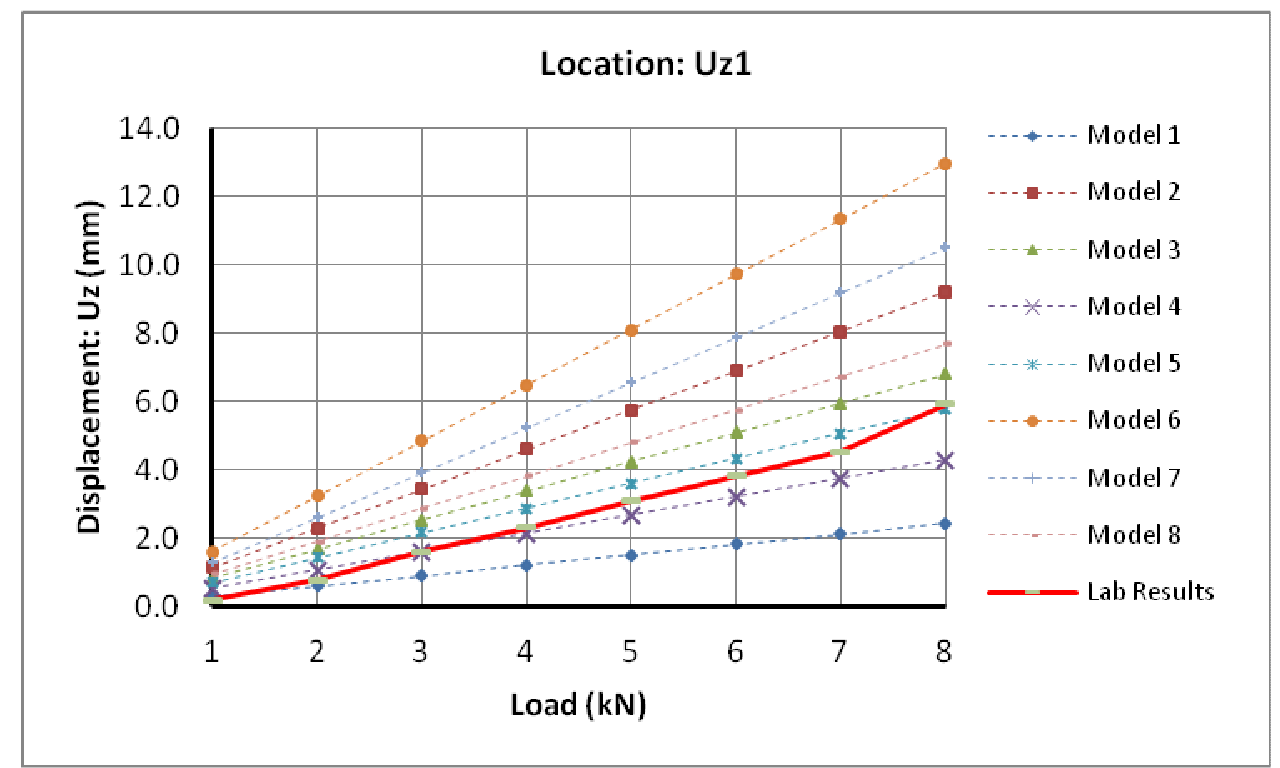

(a)

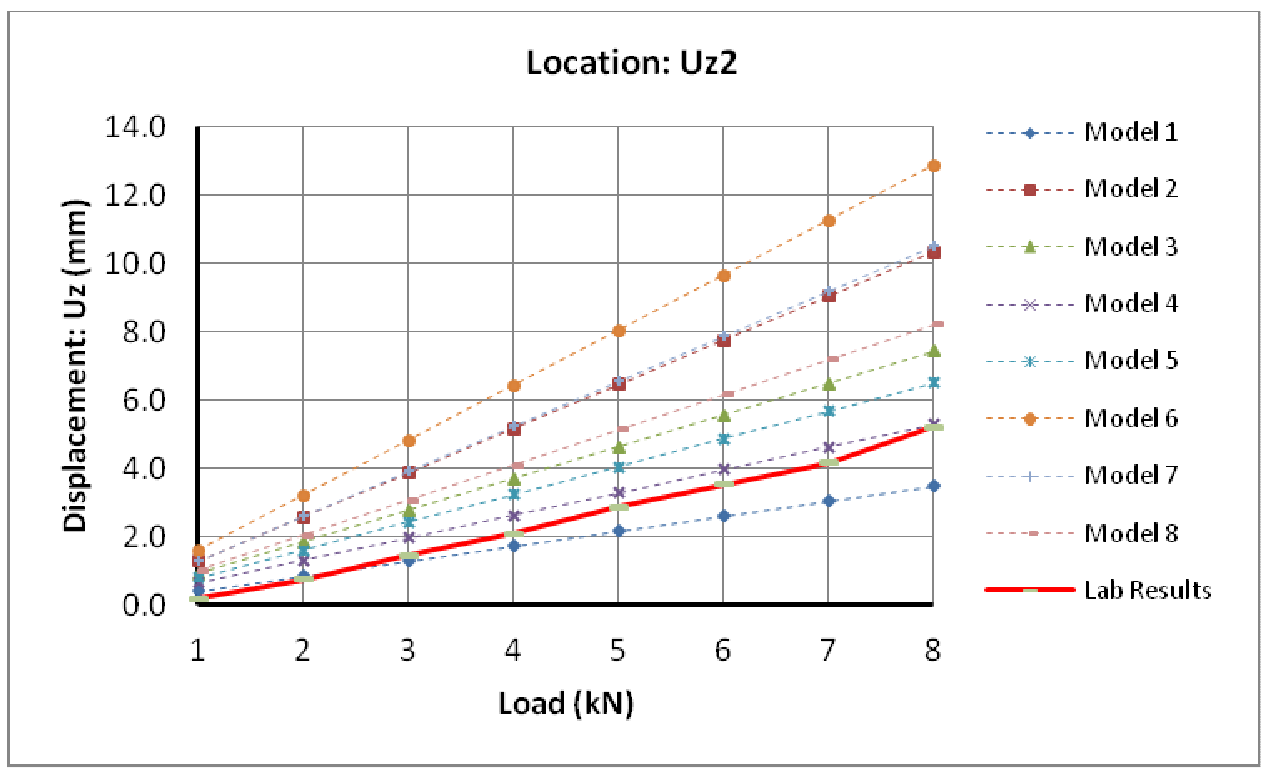

(b)

Figure 14: GSA analysis models [1 to 8] predicted and measured LVDT vertical displacements at (a) Uz1 and (b) Uz2. See Figure 6 for locations and Table 4 for analysis assumptions. 


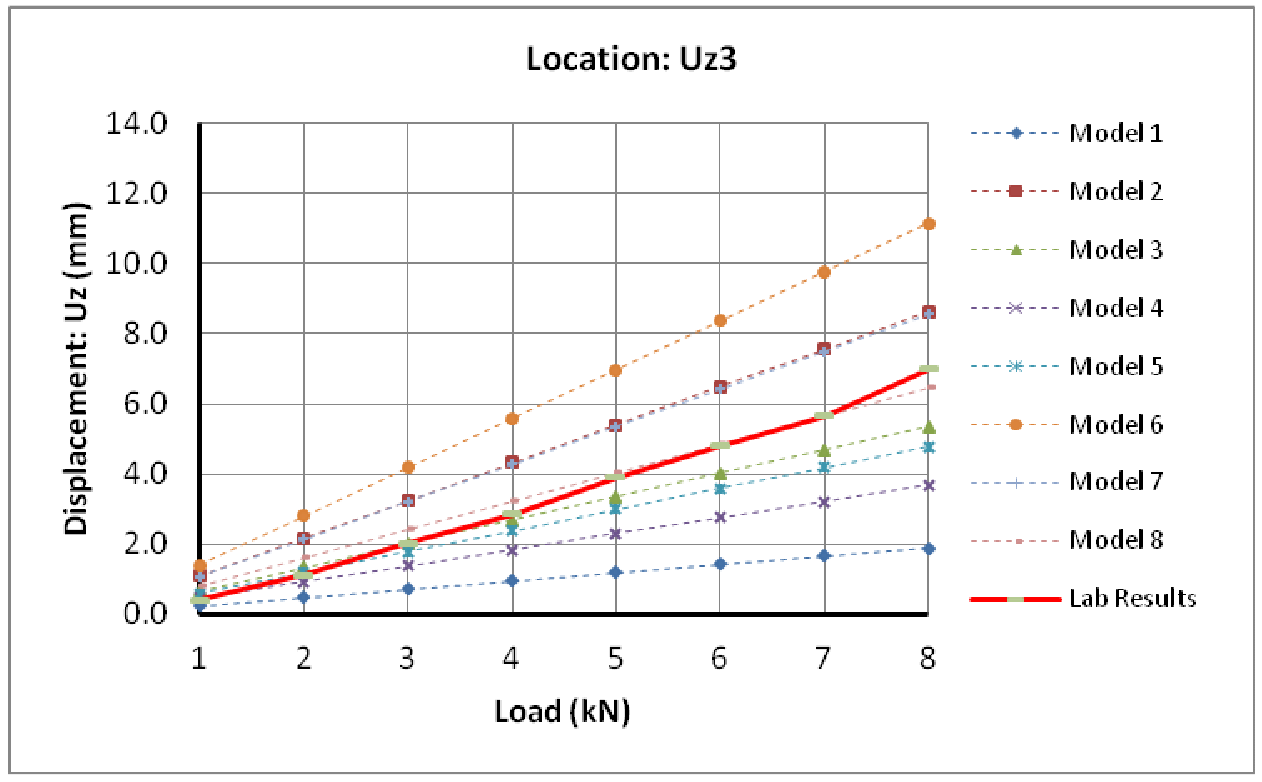

(a)

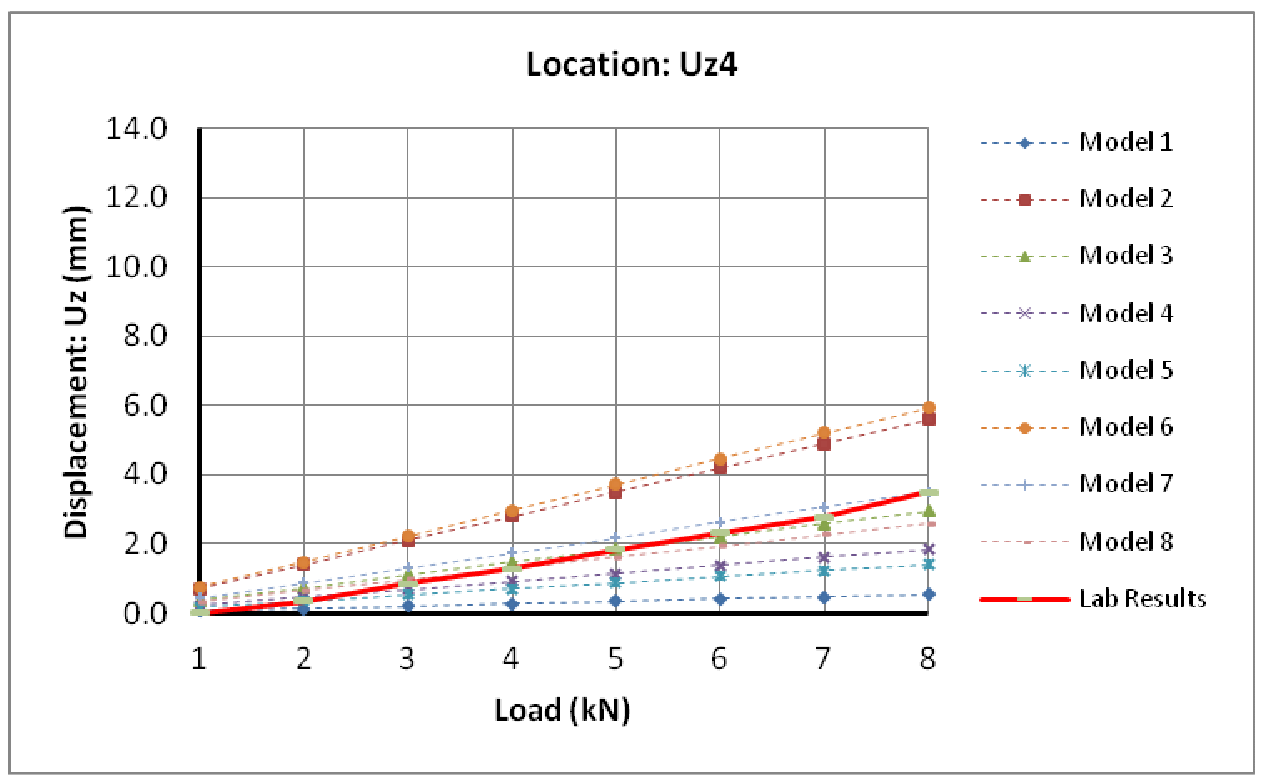

(b)

Figure 15: GSA analysis models [1 to 8] predicted and measured LVDT vertical displacements at (a) Uz3 and (b) Uz4. See Figure 6 for locations and Table 4 for analysis assumptions. 

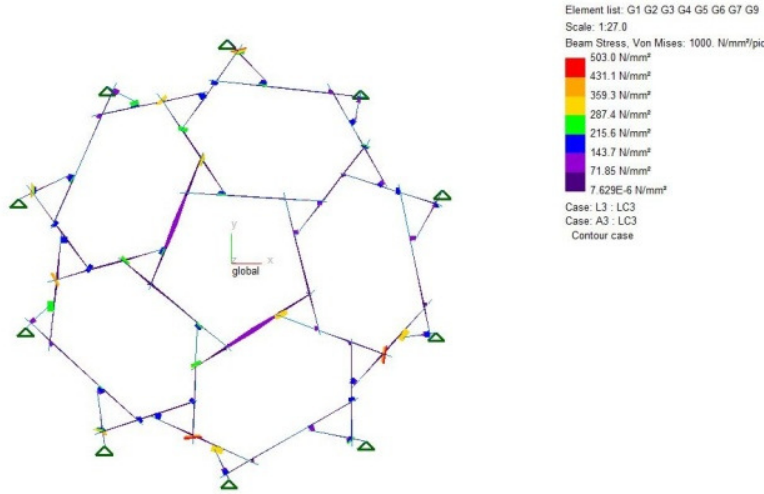

(Model 1) All supports pinned.

All connections fixed.
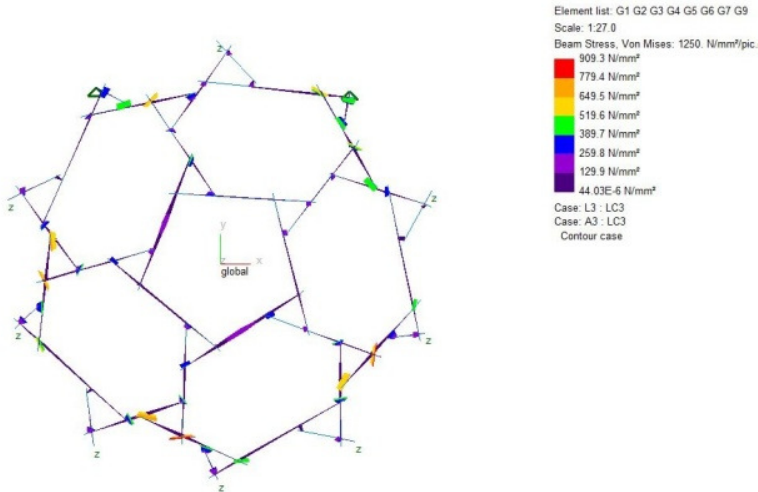

(Model 2) Two supports pinned (triangles) remainder on rollers. All connections fixed.
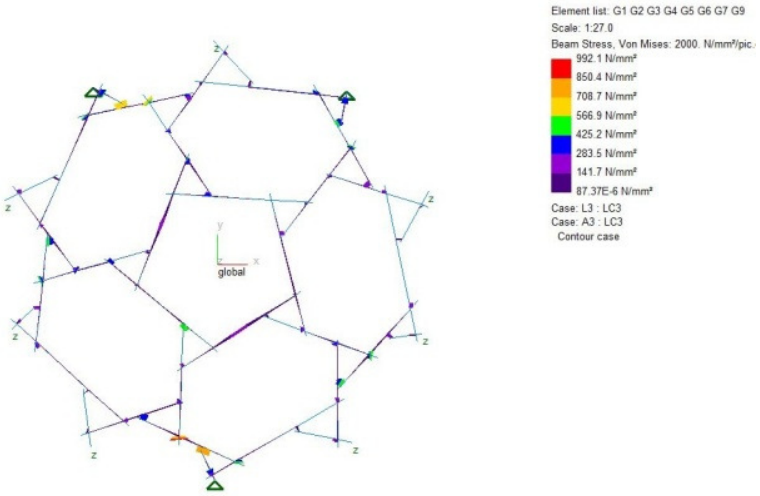

(Model 3) Three supports pinned (triangles) remainder on rollers. All connections fixed.

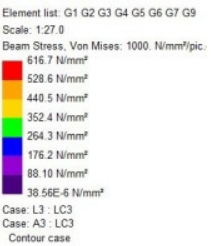

(Model 4) All supports with spring stiffnesses. All connections fixed.

Figure 16: GSA analysis models [1 to 4] predicted von Mises stresses, $\sigma_{\mathrm{MV}, \mathrm{A}}$ at $8 \mathrm{kN}$ max applied loading. Max von Mises stress, $\sigma_{\mathrm{Mv}, \mathrm{A}}(\mathrm{red})$ : Model 1: $503.0 \mathrm{~N} / \mathrm{mm}^{2}$, Model 2: $909.3 \mathrm{~N} / \mathrm{mm}^{2}$, Model 3: $992.1 \mathrm{~N} / \mathrm{mm}^{2}$ and Model 4: $616.7 \mathrm{~N} / \mathrm{mm}^{2}$. Areas highlighted in red indicate locations where material yield stress is exceeded. See Table 4 for full details of boundary support and CHS connection conditions. 

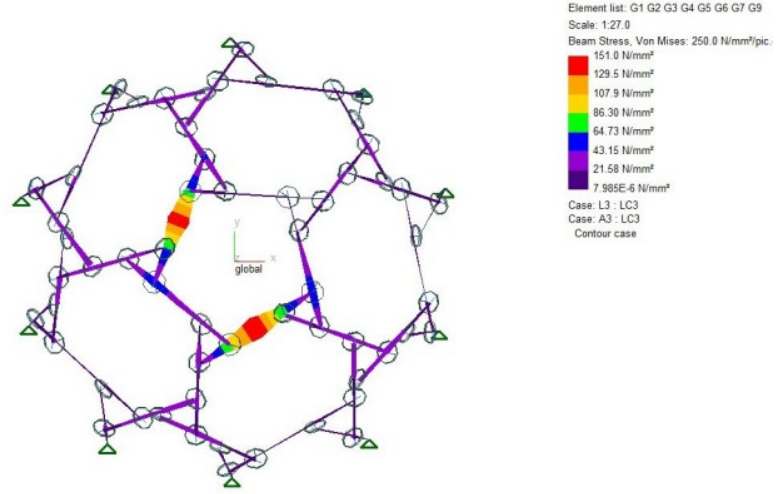

(Model 5) All supports pinned. All connections with spring stiffnesses.
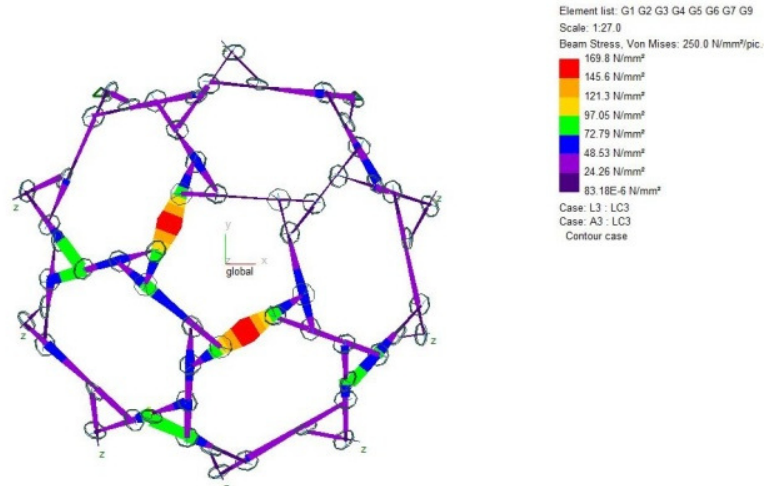

(Model 6) Two supports pinned (triangles) remainder on rollers. All connections with spring stiffnesses.
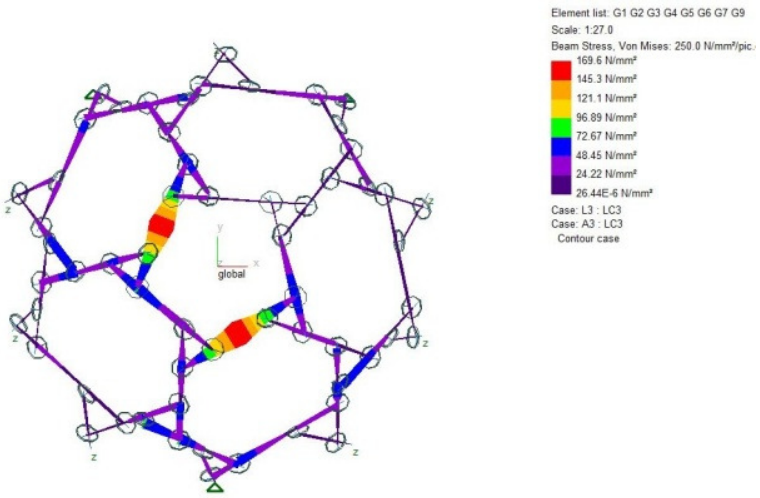

(Model 7) Three supports pinned (triangles) remainder on rollers. All connections with spring stiffnesses.
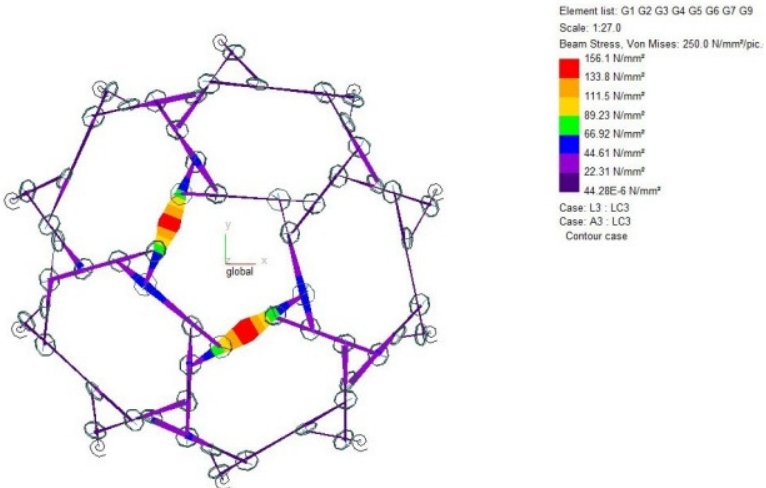

(Model 8) Supports all with spring stiffnesses. All connections with spring stiffnesses.

Figure 17: GSA analysis models [5 to 8] predicted von Mises stresses, $\sigma_{\mathrm{MV}, \mathrm{A}}$ at $8 \mathrm{kN}$ max applied loading. Max von Mises stress, $\sigma_{\mathrm{MV}, \mathrm{A}}(\mathrm{red})$ : Model 5: $151.0 \mathrm{~N} / \mathrm{mm}^{2}$, Model 6: $169.8 \mathrm{~N} / \mathrm{mm}^{2}$, Model 7: 169.6 N/mm² and Model 8: $156.1 \mathrm{~N} / \mathrm{mm}^{2}$. Material yield stress not exceeded. See Table 4 for full details of boundary support and CHS connection conditions. 


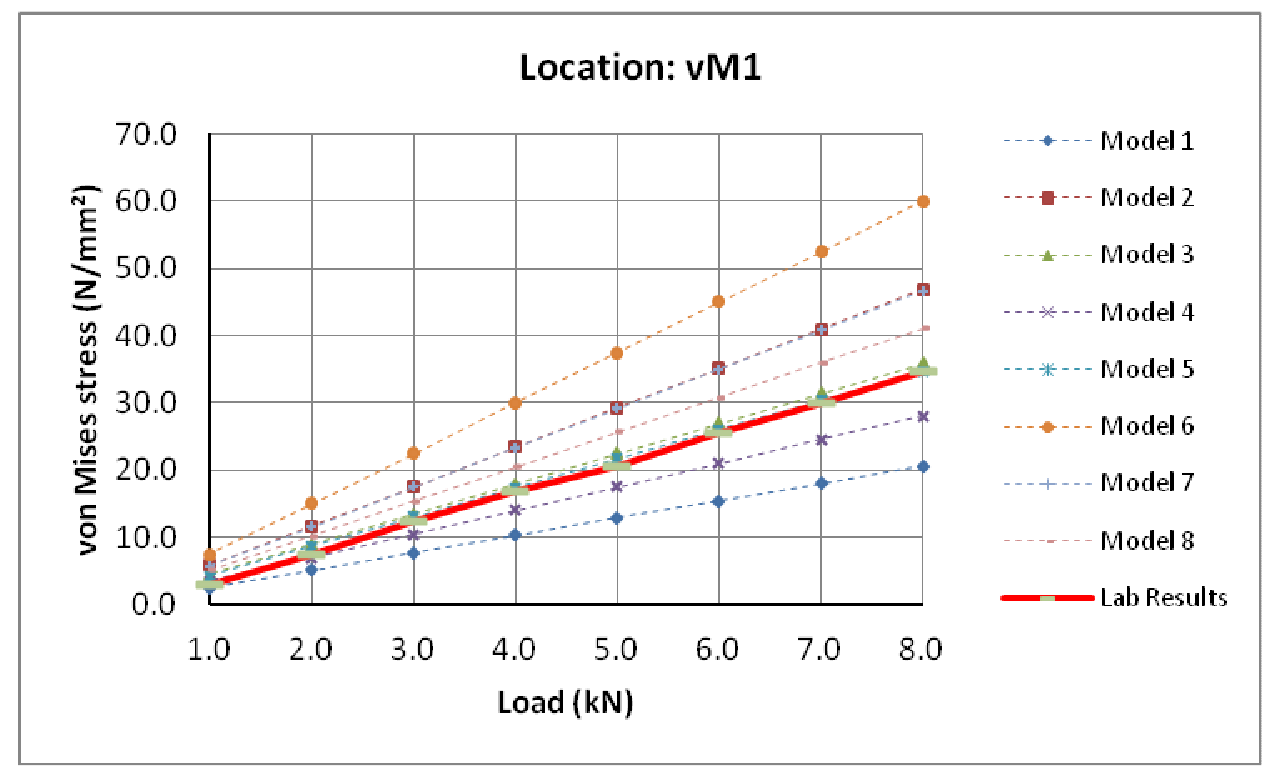

(a)

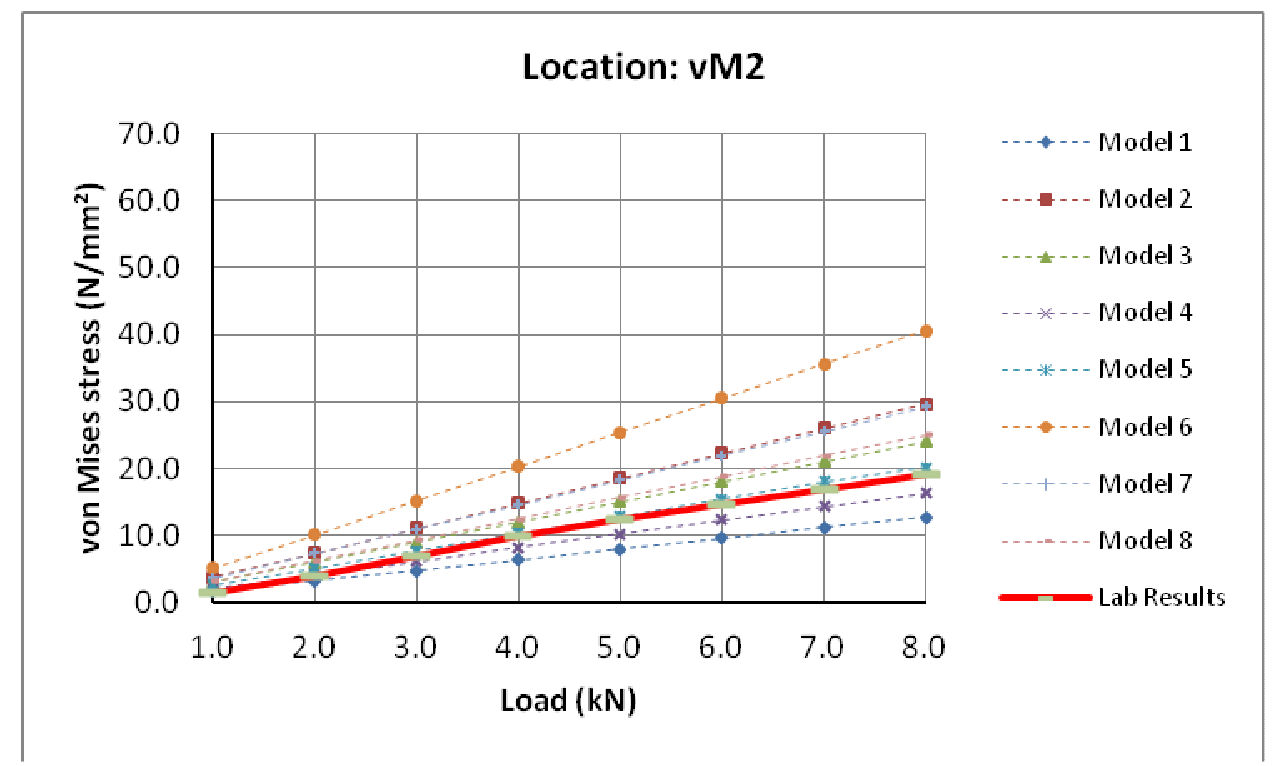

(b)

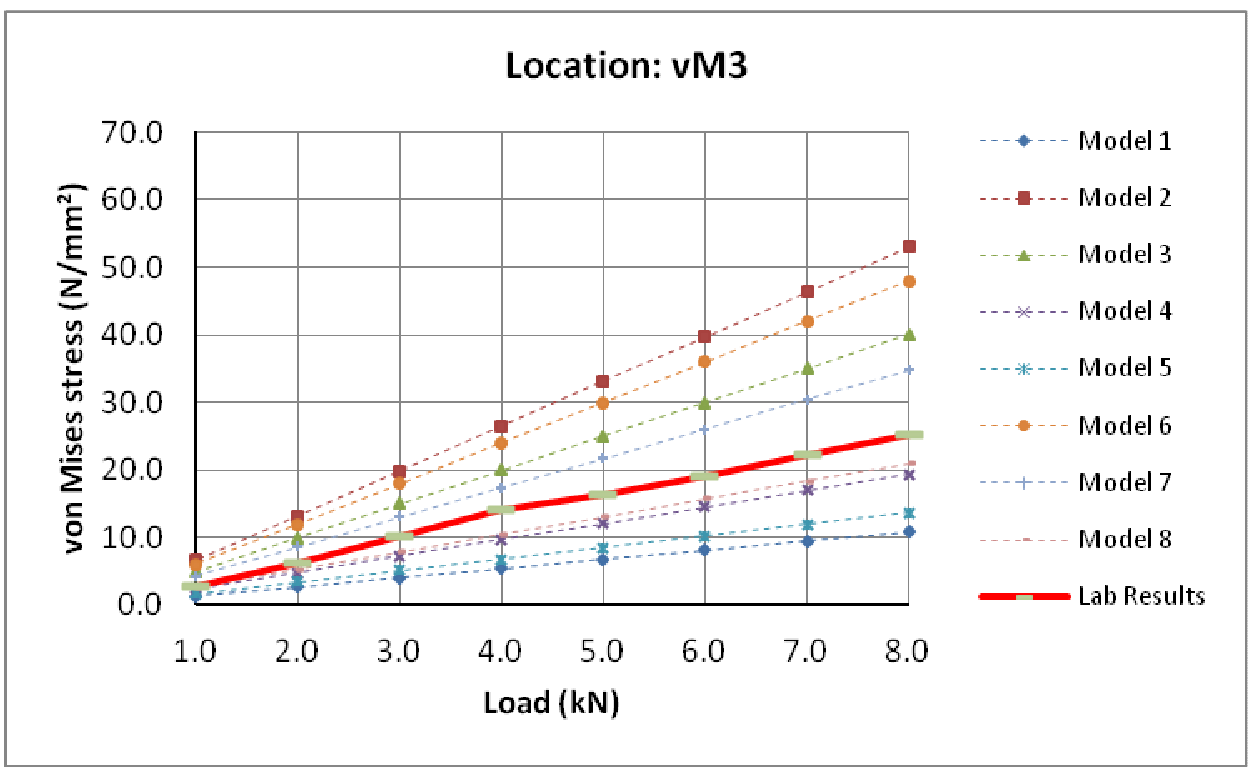

(c)

Figure 18: GSA analysis models [1 to 8] predicted and rosette strain gauge determined von Mises stresses, $\sigma_{M V, A}$ and $\sigma_{M V, L}$ at $8 \mathrm{kN}$ max loading at (a) VM1, (b) VM2 and (c) VM3. See Figure 6 for locations and Table 4 for analysis assumptions. 


\begin{tabular}{|c|c|c|}
\hline $\begin{array}{l}\text { Boundary Support } \\
\text { Condition }\end{array}$ & \multicolumn{2}{|c|}{ Description } \\
\hline 1 & \multicolumn{2}{|c|}{ All boundary supports (S1 - S10) pinned. } \\
\hline \multirow{3}{*}{2} & \multicolumn{2}{|c|}{$\begin{array}{l}\text { Static frictional resistance between boundary elements and } \\
\text { support plane exceeded. Criteria for sliding, } P>F^{\prime} \text {. }\end{array}$} \\
\hline & $\begin{array}{l}\text { Sliding force, } P \\
=\left[\left(F x^{2}+F y^{2}\right)^{0.5}\right]\end{array}$ & $\begin{array}{l}\text { Frictional resistance, } \mathrm{F}^{\prime} \\
=[\mu . \mathrm{Fz}]\end{array}$ \\
\hline & $\begin{array}{l}\text { Fx, Fy }=\text { Horizontal reaction } \\
\text { forces }\end{array}$ & $\begin{array}{l}F^{\prime}=\text { Friction force opposing } \\
\text { motion, } \mu=\text { coefficient of } \\
\text { static friction, } \mathrm{Fz}=\text { Total } \\
\text { normal reaction force. }\end{array}$ \\
\hline & \multicolumn{2}{|c|}{$\begin{array}{l}\text { Boundary support elements nodes with axial and horizontal } \\
\text { spring stiffnesses. Fz direction restrained. }\end{array}$} \\
\hline 3 & $\begin{array}{l}\text { Axial stiffness, } k=A E / L \\
A=\text { area, } E=\text { elastic modulus, } \\
L=\text { leg length. }\end{array}$ & $\begin{array}{l}\text { Horizontal spring stiffness, } \\
\mathrm{Kx}=\mathrm{Fx} / \mathrm{Ux} ; \mathrm{ky}=\mathrm{Fy} / \mathrm{Uy} \\
\text { Ux, Uy = Displacements }\end{array}$ \\
\hline
\end{tabular}

Table 1: Assumed possible boundary support conditions.

\begin{tabular}{|c|c|c|c|c|c|c|c|c|c|c|}
\hline & \multicolumn{7}{|c|}{ Boundary Nodes } \\
\cline { 2 - 10 } & $\begin{array}{c}\text { S1 } \\
(\mathrm{n} .266)\end{array}$ & $\begin{array}{c}\text { S2 } \\
(\mathrm{n} .262)\end{array}$ & $\begin{array}{c}\text { S3 } \\
(\mathrm{n} .256)\end{array}$ & $\begin{array}{c}\text { S4 } \\
(\mathrm{n} .252)\end{array}$ & $\begin{array}{c}\text { S5 } \\
(\mathrm{n} .242)\end{array}$ & $\begin{array}{c}\text { S6 } \\
(\mathrm{n} .246)\end{array}$ & $\begin{array}{c}\text { S7 } \\
(\mathrm{n} .288)\end{array}$ & $\begin{array}{c}\text { S8 } \\
(\mathrm{n} .284)\end{array}$ & $\begin{array}{c}\text { S9 } \\
(\mathrm{n} .280)\end{array}$ & $\begin{array}{c}\text { S10 } \\
(\mathrm{n} .274)\end{array}$ \\
\hline $\begin{array}{c}\mathrm{Kx} \\
{[\mathrm{kN} / \mathrm{m}]}\end{array}$ & -450.4 & -597.2 & -359.7 & -472.9 & 461.7 & -409.9 & -327.2 & -516.8 & -502.3 & -236.9 \\
\hline $\begin{array}{c}\mathrm{Ky} \\
{[\mathrm{kN} / \mathrm{m}]}\end{array}$ & -611.9 & -471.8 & -242.2 & -374.0 & -353.2 & -491.9 & -728.1 & -441.9 & -292.7 & -432.2 \\
\hline
\end{tabular}

Table 2: Boundary support nodes horizontal spring stiffnesses, kx and ky models considered. All nodes restrained in the $z$-direction.

\begin{tabular}{|l|l|l|}
\hline Spring Type & Property 1 & Property 2 \\
\hline Local axis & $\begin{array}{l}\text { Translational Linear Stiffness } \\
(\mathrm{kN} / \mathrm{m})\end{array}$ & $\begin{array}{l}\text { Rotational Linear Stiffness } \\
(\mathrm{kNm} / \mathrm{rad} .)\end{array}$ \\
\hline $\mathrm{x} / \mathrm{xx}$ & $1.63 \times 10^{5}$ & $1.57 \times 10^{2}$ \\
\hline $\mathrm{y} / \mathrm{yy}$ & $4.45 \times 10^{3}$ & $1.33 \times 10^{2}$ \\
\hline $\mathrm{z} / \mathrm{zz}$ & $1.03 \times 10^{3}$ & $1.00 \times 10^{-3}$ \\
\hline
\end{tabular}

Table 3: Connection model 2 spring stiffnesses. See Figure 6. 


\begin{tabular}{|c|c|c|c|c|c|c|c|c|}
\hline \multirow[t]{2}{*}{$\begin{array}{c}\text { Analysis } \\
\text { Model }\end{array}$} & \multicolumn{5}{|c|}{$\begin{array}{c}\text { Boundary Supports } \\
\text { Horizontal, } x \text { and } y \text {-directions. } \\
\text { Vertical z-direction restrained in all models. }\end{array}$} & \multicolumn{3}{|c|}{ RSE Connections } \\
\hline & Pin & $\mathbf{R x}$ & Ry & $\mathbf{K x}$ & Кy & Fix & $K_{T}$ & $K_{R}$ \\
\hline 1 & S1-S10 & - & - & - & - & All & - & - \\
\hline 2 & S2, S10 & S1, S3-S9 & S1, S3-S9 & - & - & All & - & - \\
\hline 3 & $\begin{array}{l}\text { S2, S6, } \\
\text { S10 }\end{array}$ & $\begin{array}{l}\text { S1, S3-S5, } \\
\text { S7-S9 }\end{array}$ & $\begin{array}{l}\text { S1, S3-S5, } \\
\text { s7-S9 }\end{array}$ & - & - & All & - & - \\
\hline 4 & - & - & - & S1-S10 & S1-S10 & All & - & - \\
\hline 5 & S1-S10 & - & - & - & - & - & All & All \\
\hline 6 & S2, S10 & S1, S3-S9 & S1, S3-S9 & - & - & - & All & All \\
\hline 7 & $\begin{array}{l}\text { S2, S6, } \\
\text { S10 }\end{array}$ & $\begin{array}{l}\text { S1, S3-S5, } \\
\text { S7-S9 }\end{array}$ & $\begin{array}{l}\text { S1, S3-S5, } \\
\text { S7-S9 }\end{array}$ & - & - & - & All & All \\
\hline 8 & - & - & - & S1-S10 & S1-S10 & - & All & All \\
\hline
\end{tabular}

Table 4: GSA analysis model assumption details where $\mathrm{Rx}, \mathrm{Ry}=$ roller supports, $\mathrm{Kx}, \mathrm{Ky}=$ spring stiffnesses, $\mathrm{K}_{\mathrm{T}}, \mathrm{K}_{\mathrm{R}}=$ Translational and Rotational spring stiffnesses.

\begin{tabular}{|c|c|c|c|c|c|}
\hline \multicolumn{2}{|c|}{$\begin{array}{l}\text { Laboratory measured } \\
\text { micro-strains }(\mu \varepsilon)\end{array}$} & \multicolumn{2}{|c|}{$\begin{array}{l}\text { Normal and shear } \\
\text { micro-strains }(\mu \varepsilon)\end{array}$} & \multicolumn{2}{|c|}{$\begin{array}{l}\text { Normal and shear } \\
\text { stresses }\left(\mathrm{N} / \mathrm{mm}^{2}\right)\end{array}$} \\
\hline$\varepsilon_{\mathrm{A}}$ & +75 & $\varepsilon_{\mathrm{x}}$ & +75 & $\sigma_{x}$ & +6.6 \\
\hline$\varepsilon_{\mathrm{B}}$ & -75 & $\varepsilon_{\mathrm{y}}$ & -153 & $\sigma_{\mathrm{y}}$ & -29.4 \\
\hline$\varepsilon_{\mathrm{c}}$ & -153 & $\gamma_{x y}$ & -72 & $\tau_{x y}$ & -5.7 \\
\hline \multicolumn{2}{|c|}{$\begin{array}{l}\text { Principal stresses } \\
\left(\mathrm{N} / \mathrm{mm}^{2}\right)\end{array}$} & \multicolumn{2}{|c|}{ Principal angles } & & \\
\hline $\operatorname{Max} \sigma_{1}$ & +7.4 & $\theta \mathrm{p}_{1}$ & $-8.8^{0}$ & & \\
\hline $\operatorname{Min} \sigma_{2}$ & -30.3 & $\theta \mathrm{p}_{2}$ & $81.2^{0}$ & & \\
\hline \multicolumn{2}{|c|}{ Shear stresses $\left(\mathrm{N} / \mathrm{mm}^{2}\right)$} & \multicolumn{2}{|c|}{ Orientation angles } & \multicolumn{2}{|c|}{$\begin{array}{l}\text { Average normal } \\
\text { stress }\left(\mathrm{N} / \mathrm{mm}^{2}\right)\end{array}$} \\
\hline $\operatorname{Max} \tau_{x y}$ & +18.6 & $\theta \mathrm{s}_{\max }$ & $36.2^{0}$ & $\sigma s$ & -11.4 \\
\hline $\operatorname{Min} \tau_{x y}$ & -18.6 & $\theta \mathrm{s}_{\min }$ & $126.2^{0}$ & $\sigma s$ & -11.4 \\
\hline \multicolumn{6}{|c|}{ Von Mises stress $\left(\mathrm{N} / \mathrm{mm}^{2}\right)$} \\
\hline$\sigma_{\mathrm{VM}, \mathrm{L}}$ & 34.6 & & & & \\
\hline
\end{tabular}

Table 5: Typical laboratory determined von Mises stress, $\sigma_{\mathrm{MV}, \mathrm{L}}$ calculation output at location vM1 under 8 kN applied loading. See Figure 6. 